\title{
Full-scale testing of stiffened extended shear tab connections under combined axial and shear forces
}

\author{
Mohammad Motallebi ${ }^{1}$, Dimitrios G. Lignos ${ }^{2}$, Colin A. Rogers ${ }^{3}$ \\ ${ }^{1}$ Graduate Research Assistant, Department of Civil Engineering and Applied Mechanics, McGill University, \\ Montreal, QC. Email: mohammad.motallebinasrabadi@mail.mcgill.ca \\ ${ }^{2}$ Dimitrios G. Lignos, Associate Professor, School of Architecture, Civil and Environmental Engineering, Swiss \\ Federal Institute of Technology, Lausanne (EPFL), Lausanne, Switzerland, Email: dimitrios.lignos@epfl.ch \\ ${ }^{3}$ Corresponding author \\ Colin A. Rogers, Associate Professor, Department of Civil Engineering and Applied Mechanics, McGill University, \\ Montreal, QC. Email: colin.rogers@megill.ca \\ 817 Sherbrooke Street West \\ Montreal QC, Canada, H3A 0C3 \\ Tel. 514 398-6449 \\ Fax. 514 398-7361
}




\section{ABSTRACT}

Owing to the lack of a comprehensive published procedure for the design of stiffened extended shear tabs, practicing engineers usually follow design guides for unstiffened shear tabs. The results of recent laboratory experiments and numerical analyses have demonstrated that improvements to this approach are warranted. Furthermore, design methods for this connection type under combined axial and shear forces are not well established. To address these shortcomings, full-scale laboratory tests were carried out on the double-sided configuration of stiffened extended beam-togirder shear tab connections with full depth shear plates. These experiments were complemented by a continuum finite element (CFE) study, with which the axial force demands along with other critical parameters that affect the connection behaviour were further examined. The experiments supported by the CFE findings indicated that the primary connection damage states are mainly associated with yielding and fracture of the shear plate due to the interaction of flexural, shear, and axial force. The study demonstrated that the direction and magnitude of the applied axial force affected significantly the shear and axial demands along the centerline of the interior bolt line. The current design practice for the double-sided configuration of the full-depth extended beam-togirder shear tab was also evaluated; a significant underestimation was observed in the prediction of a connection's ultimate resistance.

Keywords: extended shear tab, double-sided configuration, gross section yielding, plate out-ofplane deformation, net section fracture 


\section{Introduction}

Shear connections transfer the end reactions of simply supported beams to supporting columns or girders without transmitting more than $20 \%$ of the nominal plastic moment resistance of the supported beam [1]. These connections shall have sufficient ductility to sustain the rotational demands at the supported beam ends. A simple shear connection may be subjected to axial force in addition to gravity-induced shear demands due to lateral loading; hence, design for the combined action would be necessary. Furthermore, extreme loading scenarios, such as the removal of a column may cause tensile axial load in these connections. The general consensus from previously published studies is that there is little guidance regarding the design of shear connections under combined axial and shear force demands [2-4]. In particular, past editions of the American Institute of Steel Construction (AISC) Manual [5] addressed aspects related to the design of shear connections against gravity-induced shear demand, whereas the design under combined actions was mainly done based on engineering judgement. The AISC Steel Construction Manual [5] provided just an equation to define the required rotational ductility of the designed connection under combined loading. Moreover, the $15^{\text {th }}$ edition of the AISC Steel Construction Manual [2] requires the engineer to consider the interaction of axial and shear demands in the connection design procedure. Further, the AISC Steel Construction Manual [2] refers to its companion document, the AISC Design Examples [3], for design examples of simple shear connections under combined axial and shear force demands. The design procedure found in this document is similar to that described in the Steel Connection Handbook [4]; however, there is no reference to physical tests or continuum finite element (CFE) simulations in support of this procedure.

Figure 1 shows common types of simple shear tab connections used in steel construction. The $15^{\text {th }}$ edition of the AISC Steel Construction Manual [2] classifies these connections into 
conventional and extended types based on the distance between the support face and the vertical bolt line closest to the support; this is noted as the $a$ distance in Fig. 1. If this distance is larger than $89 \mathrm{~mm}$ (3.5 in.), the connection is classified as an extended shear tab. In the same figure, the geometric eccentricity, e, of the bolt group is also defined as the distance between the support face and the bolt group centre.

a

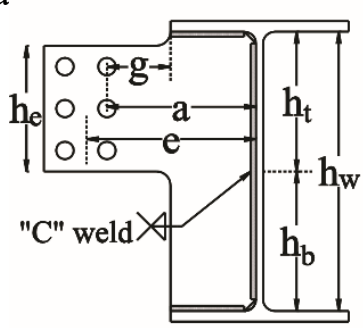

b

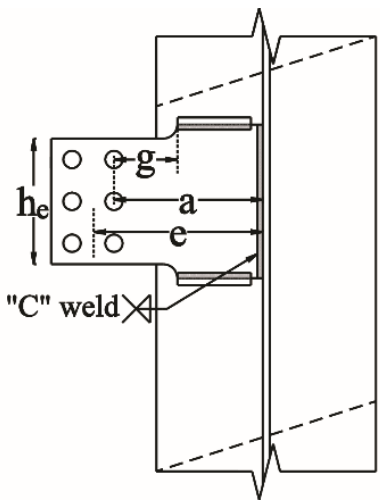

$\mathrm{c}$

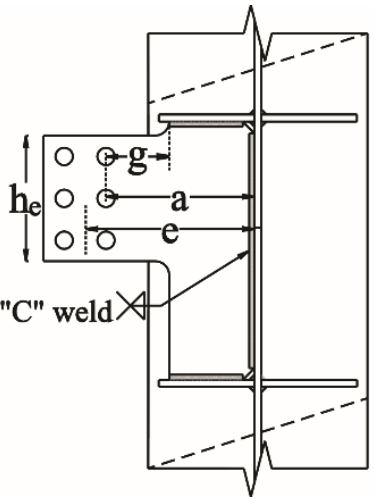

d

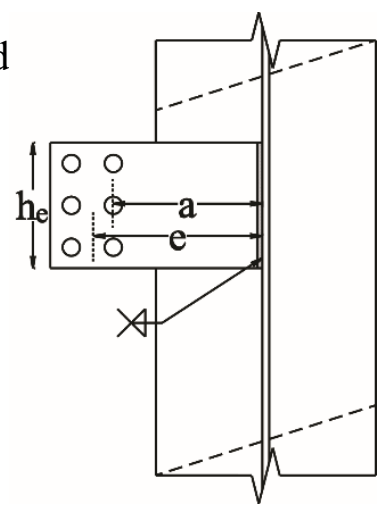

Fig. 1. Single-sided extended shear tab configurations: (a) stiffened beam-to-girder with full-depth shear plate ( $h_{w}$ definition based on CSA-S16 [6]), (b) stiffened beam-to-column, (c) stiffened beam-to-column with continuity plates, (d) unstiffened beam-to-column

Extended shear tab connections are considered as a practical and economical solution to join a simply supported beam to a column or girder web. The long plate moves the bolts clear of the support; as such, access is provided to install the bolts, and also, there is no need for coping of the beam's flange(s). The extended shear tab is a common connection configuration. A full-depth stiffener detail may be implemented in such a connection when so desired; designated as a "stiffened" configuration. The shear plate is shop-welded to the girder web and top and bottom flanges (Fig. 1a). In the case of a beam-to-column web connection (Figs. 1b and 1c), a similar detail can be realized if the shear plate is welded to the column web and to two stabilizer plates, which in turn are welded to the column flanges. Although the stiffened extended shear tab connection is used in steel construction in the USA and Canada, only a few recommendations [711] have been published for its design due to its rarity. The current AISC design approach for 
extended shear tab connections [2] was developed for unstiffened connections (Fig. 1d). In this configuration, only the vertical edge of the plate is welded to the support; its horizontal edges are laterally unrestrained. Prior studies demonstrated that plate buckling is often the governing damage state for stiffened full-depth configurations of either beam-to-girder [7-10] or beam-to-column shear tab connections [11]. The focus of these research programs was limited to the single-sided configuration of stiffened extended shear tabs under gravity-induced shear force.

Regarding the behaviour of stiffened extended shear tab connections under combined axial and shear forces, Thomas et al. $[12,13]$ focused on the single-sided configuration, similar to that shown in Fig. 1b. This configuration would need to be modified if continuity plates were incorporated into a fully restrained beam-to-column connection (Fig. 1c). In this case, the horizontal stiffeners (continuity plates) are placed along the beam flanges connected to the column's strong axis, which is usually much deeper than the simply supported beam connected to the column's weak axis. The top surface of the beams are typically specified to be at the same height, which would require the shear tab to be placed closer to the upper horizontal stiffener as shown in Fig.1c. Thomas et al. [12, 13] determined the shear plate's out-of-plane deformation to be the critical damage state, while acknowledging that the plate completely yielded prior to the onset of the connection's shear strength degradation. In all cases that were physically tested, specimens comprised columns with relatively low weak-axis stiffness; thus, a fairly small axial force demand was applied. Nevertheless stiffened extended shear tabs may experience large axial forces in real buildings; e.g. the double-sided configuration, which provides a load path to transfer axial force. Even the single-sided stiffened extended beam-to-girder shear tab may experience a large axial force, with lateral forces transferring to the supported concrete slab (diaphragm). Furthermore, the single-sided shear tab connection may resist a large axial force due to wind load 
acting on the cladding of a building. Hence, the behaviour of stiffened extended shear tab connections should be evaluated under a wide axial force range to comprehend the behaviour of such a connection under combined axial and shear force demands.

This paper presents the results of a coordinated experimental-numerical study aiming to comprehend the behaviour of the stiffened extended beam-to-girder shear tab under combined axial and shear forces. The full-scale connection tests characterized the inelastic behaviour of the stiffened extended shear tab, and were then used to benchmark continuum finite element (CFE) models. Based on the experimental and numerical results, probable damage states and their influential parameters were determined. The predictions obtained using the current AISC design procedure for extended shear tab connections were compared with the laboratory tests and CFE observations to evaluate the accuracy of the current design practice in the case of double-sided stiffened extended beam-to-girder shear tab connections with full depth shear plates.

\section{Full-scale laboratory testing}

To examine the behaviour of stiffened extended shear tabs under combined axial and shear forces, two full-scale connection specimens representing the current design practice in the USA and Canada were tested in the Jamieson Structures Laboratory at McGill University. These experiments were part of an extensive laboratory testing program [14-19] aiming toward improving the current design and detailing provisions for shear tab connections. The rationale behind choosing the double-sided configuration was its ability to provide a load path for passthrough forces, allowing the connection to experience a wide range of axial and shear force demands. Therefore, a shear-axial force interaction curve could be developed in consideration of a shear tab's damage states. 


\subsection{Description of test specimens}

The specimens varied with respect to the number of rows of bolts and the dimensions of the shear plate, including its depth, length, and thickness (Fig. 2). The specimen ID, e.g. BG3-2-13-F200C, identifies the following: BG stands for beam-to-girder configuration, 3 represents the number of rows of bolts, 2 shows the number of vertical bolt lines, 13 demonstrates the thickness of shear plate (mm), F indicates that a full-depth shear plate was used, and 200C represents the magnitude $(200 \mathrm{kN})$ and direction (Compression) of the applied axial force.
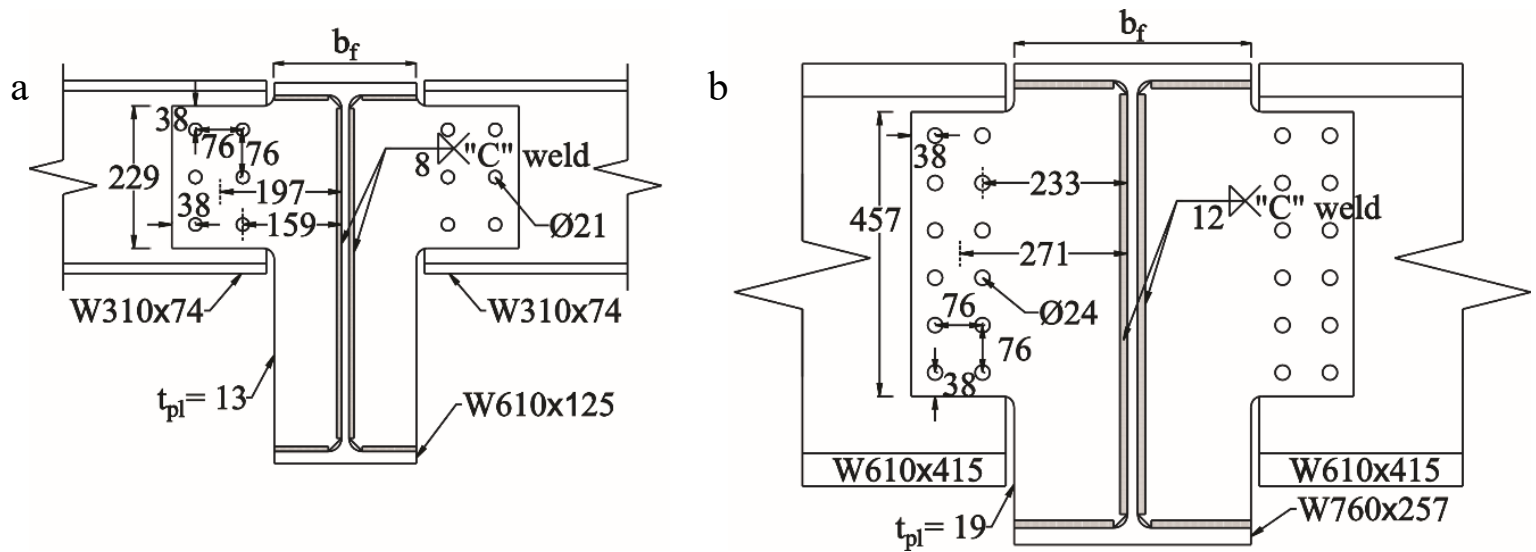

Fig. 2. Double-sided configuration of test specimens: (a) BG3-2-13-F-200C, (b) BG6-2-19-F-500C

In both specimens, the slenderness ratio $\left(\mathrm{b}_{\mathrm{f}} / 2 \mathrm{t}_{\mathrm{pl}}\right)$ of the shear plate satisfied the CSA-S16 compactness requirement [6] for plate girder stiffeners $\left(200 / \sqrt{F_{y}}=10.7\right)$. However, this is not a requirement for the existing AISC design method [2] because local buckling is not a concern for an unstiffened extended shear tab. Prior studies [8-10] demonstrated the influence of the shear plate compactness on the ductile response of single-sided shear tab connections.

Considering the symmetry of a double-sided shear tab along the girder axis, the laboratory specimens consisted of only half of the girder and the shear tab connection on that side (Fig. 3). Prior research indicated that the behaviour of single- and double-sided shear tabs is different due to the distortion of the girder web [10]. To simulate one side of the girder, two steel plates were 
joined to the column flange using a complete joint penetration (CJP) weld. The plate dimensions were chosen to be representative of the half width of the girder flange. The shear plate was connected to these steel plates and the column flange, through a fillet weld, which was detailed according to the extended shear tab requirements of the AISC Manual [2]. The in-plane displacement of the column was restricted using two back-braces attached to the strong-floor of the laboratory (see Section 2.2). Furthermore, the bottom flange of each beam was coped to increase the beam-plate gap, and consequently delay beam flange binding with the shear tab. Preliminary CFE analyses suggested that these short copes would not affect the connection's global response.
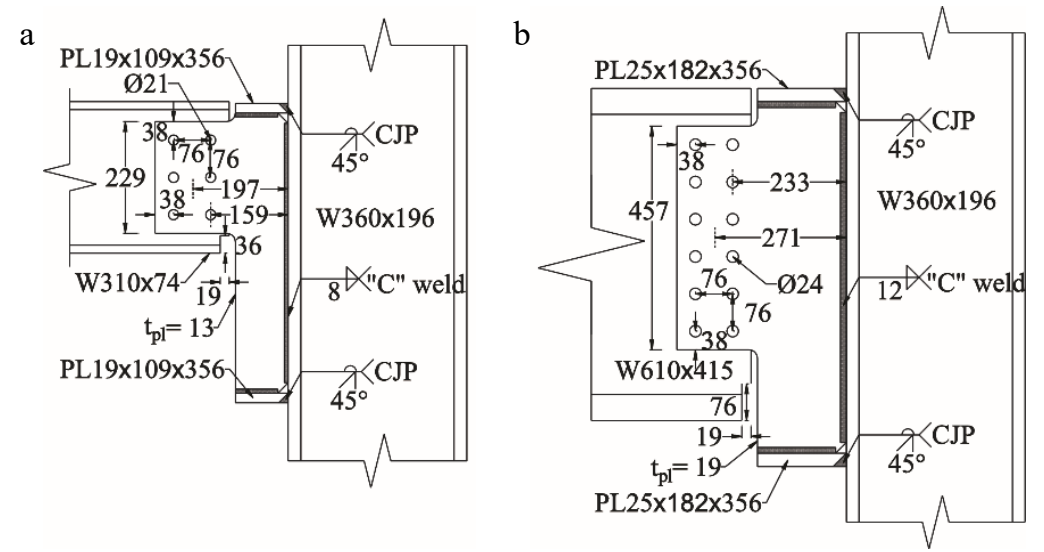

Fig. 3. Details of test specimens: (a) BG3-2-13-F-200C, (b) BG6-2-19-F-500C

The beams and girders were fabricated from ASTM A992 Grade $50\left(\mathrm{~F}_{\mathrm{y}}=345 \mathrm{MPa}\right)$ steel [20], while the shear plates were made of ASTM A572 Grade $50\left(F_{y}=345 \mathrm{MPa}\right)$ steel [21]. To attach the shear tab to the fabricated supporting girder, an E71T electrode $\left(\mathrm{X}_{\mathrm{u}}=490 \mathrm{MPa}\right)$ [22] was used in a flux-cored arc welding process with additional shielding gas $\left(\mathrm{CO}_{2}\right)$ to provide a fillet weld on both sides of the plate. Each beam was snug-tightened to the shear tab using ASTM F3125 Grade A490 bolts [23] in standard size holes, $2 \mathrm{~mm}$ (1/16") larger in diameter than the bolts. Figure 4 shows these two specimens during installation and just prior to testing. 
a

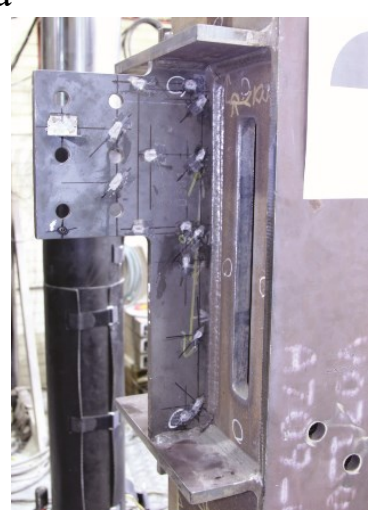

$\mathrm{b}$

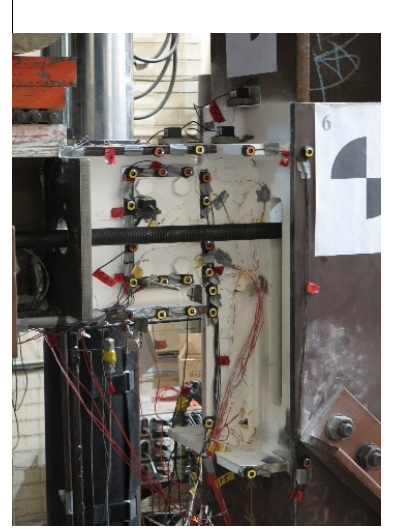

$\mathrm{C}$

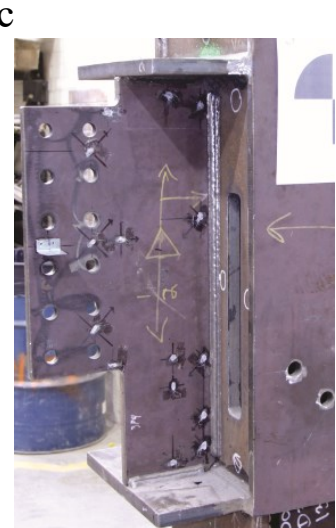

d

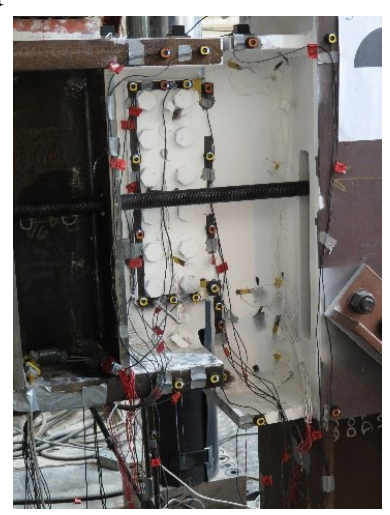

Fig. 4. Specimens: (a \& b) BG3-2-13-F-200C, (c\&d) BG6-2-19-F-500C

Table 1 shows the nominal and expected strength of the connection components, along with their measured material properties obtained by ancillary tests in the form of steel and all-weld tensile coupon tests. The test coupons of the shear plates and beams (including web and flanges) were extracted from the same batch of full-scale test components. For each beam, four coupons were cut from the flanges, while three were cut from the web. Six coupons were taken from each plate thickness, three along and three perpendicular to the grain direction.

Table 1. Material properties of individual steel components

\begin{tabular}{|c|c|c|c|c|c|c|}
\hline \multirow[b]{2}{*}{$\begin{array}{c}\text { Individual } \\
\text { steel components }\end{array}$} & \multicolumn{2}{|c|}{ Nominal } & \multicolumn{2}{|c|}{ Probable $^{1}$} & \multicolumn{2}{|c|}{ Measured } \\
\hline & $\begin{array}{c}\mathrm{F}_{\mathrm{y}} \\
(\mathrm{MPa})\end{array}$ & $\begin{array}{c}\mathrm{F}_{\mathrm{u}} \\
(\mathrm{MPa})\end{array}$ & $\begin{array}{c}\mathrm{F}_{\mathrm{y}} \\
(\mathrm{MPa})\end{array}$ & $\begin{array}{c}\mathrm{F}_{\mathrm{u}} \\
(\mathrm{MPa})\end{array}$ & $\begin{array}{c}\mathrm{F}_{\mathrm{y}} \\
(\mathrm{MPa})\end{array}$ & $\begin{array}{c}\mathrm{F}_{\mathrm{u}} \\
(\mathrm{MPa})\end{array}$ \\
\hline W310×74 & 345 & 448 & 379 & 493 & 374 & 490 \\
\hline$(\mathrm{W} 12 \times 50)$ & 345 & 448 & 379 & 493 & 379 & 495 \\
\hline $\mathrm{W} 610 \times 415$ & 345 & 448 & 379 & 493 & 372 & 513 \\
\hline (W24×279) & 345 & 448 & 379 & 493 & 377 & 507 \\
\hline $13 \mathrm{~mm}(1 / 2 ")$ plates & 345 & 448 & 379 & 538 & 432 & 508 \\
\hline $19 \mathrm{~mm}(3 / 4$ ') plates & 345 & 448 & 379 & 538 & 377 & 527 \\
\hline E71T electrode & 400 & 490 & -- & -- & 548 & 620 \\
\hline A490 bolts & 896 & 1034 & -- & -- & -- & -- \\
\hline
\end{tabular}

${ }^{1} \mathrm{R}_{\mathrm{y}} \mathrm{F}_{\mathrm{y}}$ and $\mathrm{R}_{\mathrm{T}} \mathrm{F}_{\mathrm{u}}$; for steel plates $1.1 \mathrm{~F}_{\mathrm{y}}$ and $1.2 \mathrm{~F}_{\mathrm{u}}$ while $1.1 \mathrm{~F}_{\mathrm{y}}$ and $1.1 \mathrm{~F}_{\mathrm{u}}$ for hot-rolled structural shapes [24]

All steel coupons were tested based on ASTM A370 [25], except that the two all-weld coupons were tested based on AWS A5.20 [26]. The all-weld coupons were extracted from a groove welded assembly of two plates, fabricated from the same electrodes used for the shear tab specimens [26, 27]. As neither bolt fracture, nor bolt deformation was observed in these tests, bolt shear tests were not conducted. 
The specimens were designed based on the current AISC procedure [2] applicable to unstiffened extended shear tabs. To calculate the bolt group capacity, the geometric eccentricity, e (shown in Fig. 1), was chosen as the bolt group eccentricity. As such, the bolt group was designed for the beam end shear reaction $(\mathrm{V})$ and its eccentric bending moment $(\mathrm{V} \times \mathrm{e})$. The axial force $(\mathrm{P})$ was accounted for by controlling the bolt group capacity for the resultant of the axial and shear forces $\left(\mathrm{R}=\sqrt{\mathrm{V}^{2}+\mathrm{P}^{2}}\right)$ and the eccentric bending moment $(\mathrm{V} \times \mathrm{e})$. The weld line was designed to concentrically resist the beam end reaction (R). To ensure ductile behaviour of the shear tab connection, the weld throat and the plate thickness were detailed such that yielding can develop over the full height of the shear plate's extended portion ( $h_{e}$ in Fig. 1) prior to bolt shear fracture and/or weld tearing. The flexural buckling strength of the shear plate was calculated based on the two available AISC design methods [2,5]. The latest method [2] is used to estimate the shear tab's buckling strength based on the rectangular plate buckling model $[1,28]$ to address the higher probability of occurrence of shear plate instability, because of the large eccentricity. Earlier editions [5] used models representative of the flexural buckling of a doubly coped beam [29-31]. To calculate the buckling strength, the distance between the girder web and the interior bolt line ( $a$ distance) was conservatively chosen to be the unbraced length of the shear plate. Both methods predicted that buckling would not prevent the shear plate from reaching its fully plastic flexural capacity $\left(\mathrm{M}_{\mathrm{p}}=\mathrm{F}_{\mathrm{y}} \mathrm{Z}_{\mathrm{p}}\right)$. Regarding the shear tab design, the AISC Steel Construction Manual [2] considers the interaction of the shear and bending moment by using an elliptical interaction equation (Eq. (1)). The AISC Design Examples (Example IIA-19B) [3] and the Steel Connection Handbook (Section 2.5.3) [4] use Eq. (2) to calculate the yield strength of the plate due to the interaction of the bending, shear, and axial force. This equation was based on Eq. (1) and the design 
requirement of Section H1.1 of the AISC 360 Specification [1] for doubly symmetric members subjected to flexure and axial force.

$$
\begin{aligned}
& \left(\frac{M}{M_{P}}\right)^{2}+\left(\frac{V}{V_{P}}\right)^{2} \leq 1 \\
& \left(\frac{P}{2 P_{P}}+\frac{M}{M_{P}}\right)^{2}+\left(\frac{V}{V_{P}}\right)^{2} \leq 1 \quad \frac{P}{P_{P}}<0.2 \\
& \left(\frac{P}{P_{P}}+\frac{8}{9} \frac{M}{M_{P}}\right)^{2}+\left(\frac{V}{V_{P}}\right)^{2} \leq 1 \quad 0.2 \geq \frac{P}{P_{P}}
\end{aligned}
$$

Table 2 summarizes the calculated connection strengths corresponding to its probable damage states. The expected capacity of the connection was calculated based on the probable material properties of the steel plate (Table 1), whereas the nominal properties of the bolt and the welding electrode were implemented. Furthermore, the resistance factors ( $\phi$ factors) were excluded from the calculation of the connections' expected strengths.

Table 2. AISC predicted strength of shear tab test specimens

\begin{tabular}{ccccccc}
\hline & \multicolumn{3}{c}{ BG3-2-13-F-200C } & \multicolumn{3}{c}{ BG6-2-19-F-500C } \\
\hline Damage state & $\begin{array}{c}\text { Design } \\
\text { strength } \\
(\mathrm{kN})\end{array}$ & $\begin{array}{c}\text { Expected } \\
\text { strength }^{1} \\
(\mathrm{kN})\end{array}$ & $\begin{array}{c}\text { Expected } \\
\text { strength }^{2} \\
(\mathrm{kN})\end{array}$ & $\begin{array}{c}\text { Design } \\
\text { strength } \\
(\mathrm{kN})\end{array}$ & $\begin{array}{c}\text { Expected }_{\text {strength }^{1}} \\
(\mathrm{kN})\end{array}$ & $\begin{array}{c}\text { Expected } \\
\text { strength }^{3} \\
(\mathrm{kN})\end{array}$ \\
\hline Flexural-shear-axial yielding & 254 & 329 & 365 & 991 & 1180 & 1171 \\
Shear yielding of shear plate & 616 & 678 & 761 & 1835 & 2018 & 1976 \\
Bolt bearing & 250 & 367 & 367 & 1137 & 1820 & 1725 \\
Flexural buckling of shear plate & 333 & 407 & 456 & 1351 & 1651 & 1616 \\
Shear rupture at net section of shear plate & 430 & 688 & 648 & 1207 & 1931 & 1824 \\
Bolt shear & 221 & 327 & 327 & 746 & 1105 & 1105 \\
Weld tearing & 1512 & 2016 & 2544 & 2657 & 3543 & 4505 \\
\hline
\end{tabular}

${ }^{1}$ Expected strength based on probable material properties i.e. $\mathrm{R}_{\mathrm{y}} \mathrm{F}_{\mathrm{y}}\left(1.1 \mathrm{~F}_{\mathrm{y}}\right)$ and $\mathrm{R}_{\mathrm{T}} \mathrm{F}_{\mathrm{u}}\left(1.2 \mathrm{~F}_{\mathrm{u}}\right)$ for steel plates [24]

${ }^{2}$ Expected strength based on measured material properties i.e $\mathrm{F}_{\mathrm{y}}=432 \mathrm{MPa}$ and $\mathrm{F}_{\mathrm{y}}=508 \mathrm{MPa}$ for $13 \mathrm{~mm}$ plate

${ }^{3}$ Expected strength based on measured material properties i.e $\mathrm{F}_{\mathrm{y}}=377 \mathrm{MPa}$ and $\mathrm{F}_{\mathrm{y}}=527 \mathrm{MPa}$ for $19 \mathrm{~mm}$ plate

Referring to the design and expected strength calculations of Table 2, bolt shear fracture was predicted to be the governing damage state of the connection. Albeit this prediction was in contrast with findings from prior research [7-13], the aim of the AISC design method is to provide a reasonably conservative estimate of the connection's capacity, without demanding an overly 
complex design procedure. To this end, the AISC calculated bolt group capacity is based on the geometric eccentricity (e), as depicted in Fig. 1. The measured material properties of the beam, girder, plate, and weld (Table 1) were also used to conduct the above AISC-based calculations, whereas the nominal properties of the bolts were relied on in this process.

\subsection{Test setup}

Figure 5a illustrates the test setup, which features a $12 \mathrm{MN}$ and a $445 \mathrm{kN}$ hydraulic actuator, a lateral bracing system for the steel beam, supporting elements for the connection, and an axial load application system. The $12 \mathrm{MN}$ actuator was located near the shear tab connection; it developed the main shear force in the connection. The $445 \mathrm{kN}$ actuator, placed near the far end of the beam, facilitated the vertical displacement control of the beam tip, as well as the connection rotation. The lateral bracing system was installed to restrict the lateral displacement of the beam, without affecting its vertical displacement. The overall test setup was similar to that used in prior studies $[8,9,14-19,32,33]$.

The axial load application system, shown in Fig. 5b, was used to maintain a constant axial force on the connection normal to the beam's cross-section, while following the beam end rotation. Slots on the column flanges allowed two threaded $31.8 \mathrm{~mm}\left(1 \frac{1 / 4}{4}\right)$ steel rods to pass through and transfer the axial load to a heavily reinforced region of the beam. Further, these rods passed through the moving plate and half cylinder, which allowed for control of the rods' rotation and vertical displacement, respectively. The axial force was generated by two horizontal Enerpac RRH-3010 hydraulic jacks, while the vertical displacement of the moving plate was controlled by a vertical $31.8 \mathrm{~mm}\left(1 \mathrm{1} / 4^{\prime \prime}\right)$ steel rod installed through another similar Enerpac cylinder. 

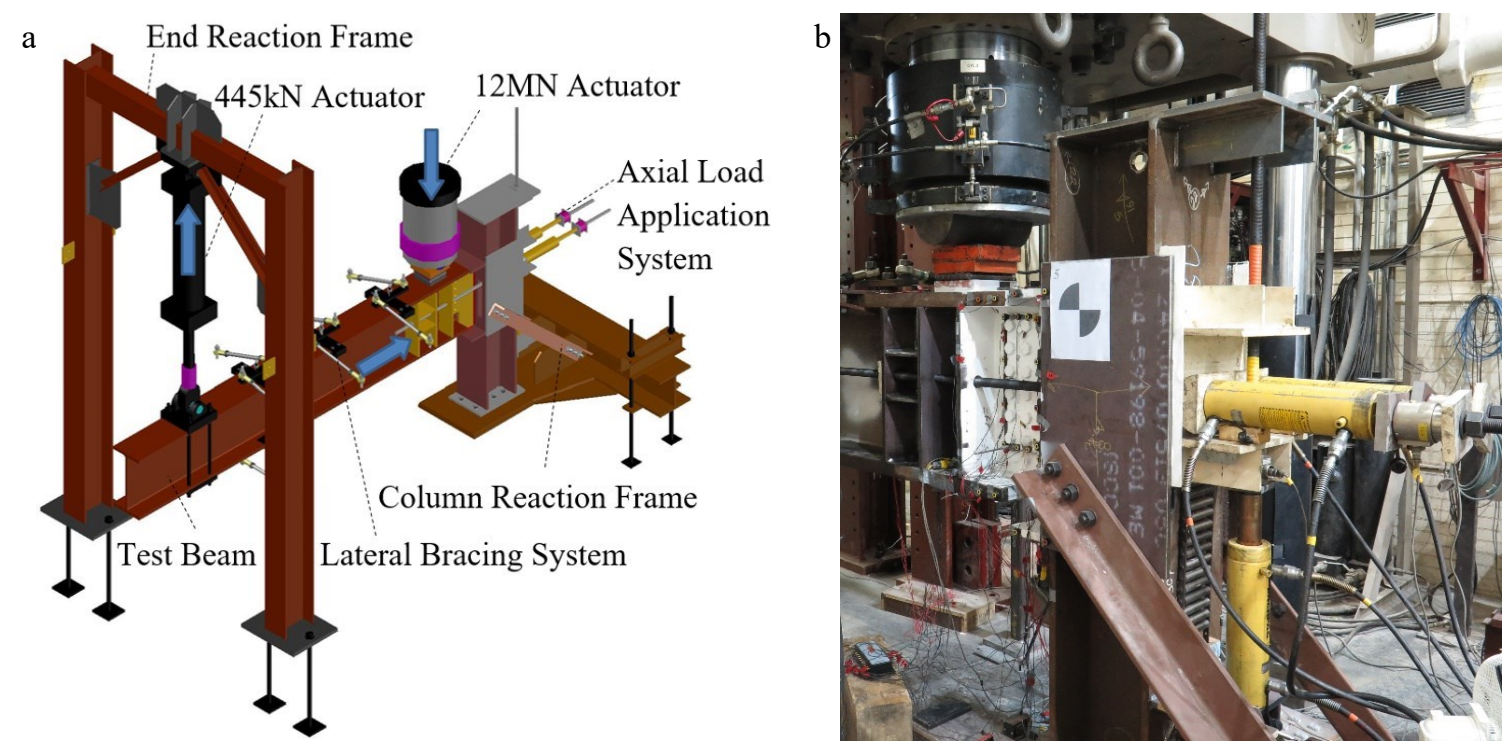

Fig. 5. Laboratory tests: (a) test setup, (b) axial load application system

\subsection{Instrumentation}

The instrumentation included an optical Coordinate-Measuring Machine (CMM) for 3D wireless tracking measurements of the connection deformation at discrete points (Fig. 6a). Linear Variable Differential Transformers (LVDTs) were installed to measure the out-of-plane deformations as a backup of the optical CMM system (Fig. 6b). Inclinometers measured the inplane rotation of the beam, top girder flange, shear plate, and column. The out-of-plane rotations of the shear plate and beam were also measured. String potentiometers were used to measure the vertical deformation of the beam and shear plate, as well as the horizontal displacement of the column capping plate. The connection was whitewashed to observe the associated yielding pattern that was also monitored with strain gauges installed on the shear plate, beam web and flanges adjacent to the connection (Fig. 6c). Load cells were used to monitor the applied vertical and horizontal forces. Vishay Model 5100B scanners and the Vishay System 5000 StrainSmart software were used to record the measured data. 

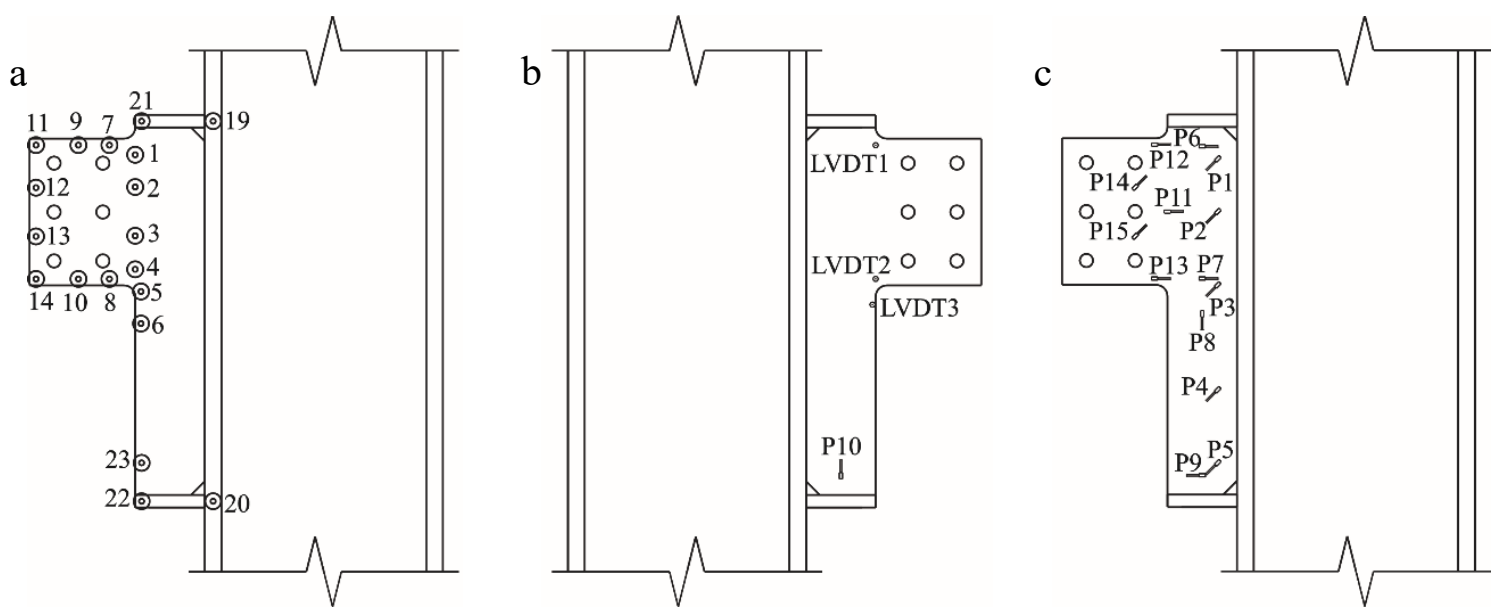

Fig. 6. Instrumentation of Specimen BG3-2-13-F-200C: (a) targets of optical CMM system, (b) LVDTs, (c) strain gauges

\subsection{Loading protocol}

The loading protocol was chosen to simulate the end demands of a simply supported beam when subjected to coupled axial and shear force. As such, each test specimen was first subjected to its service level of shear load, followed by the application of an axial force. From this point on, the axial force was kept constant, under load control, while the shear demand (deformation/rotation control) was increased until significant degradation of the connection shear force was observed. Previous research [17] suggested that local yielding of the shear tab is typically observed prior to reaching the service shear load on the connection. Therefore, the axial force was applied in advance of the onset of yielding based on real time monitoring of strain gauge data. For both specimens, the axial force was applied at a connection rotation of approximately $0.0085 \mathrm{rad}$.

To replicate the rotational demand at the end of a simply supported beam under gravityinduced shear force, 0.02 rad relative rotation between the beam and column was set as a target. This target rotation was achieved at the connection's probable shear resistance, which was calculated based on the expected material properties in lieu of measured ones, as coupons tests were conducted only after the full-scale tests. The probable resistance was calculated according to 
the AISC design method with the resistance factors set equal to one. This was deemed a rational approach based on prior research $[32,33]$. To follow the loading protocol, the ratio between the displacement rates of the actuators was continuously adjusted up to the target rotation / load point; after reaching this level, the ratio between displacement rates of the actuators was held constant.

\subsection{Experimental results and discussion}

Figure 7 shows the shear force and displacement response of both specimens versus the connection rotation, i.e. the relative rotation between the beam and girder measured at the top flange of the girder. The measured connection shear force was normalized by the shear force corresponding to the plastic shear resistance of the plate's gross section $\left(h_{e}\right.$ in Fig. 1$)$, which is equal to $761 \mathrm{kN}$ and $1976 \mathrm{kN}$ for Specimens BG3-2-13-F and BG6-2-19-F, respectively.
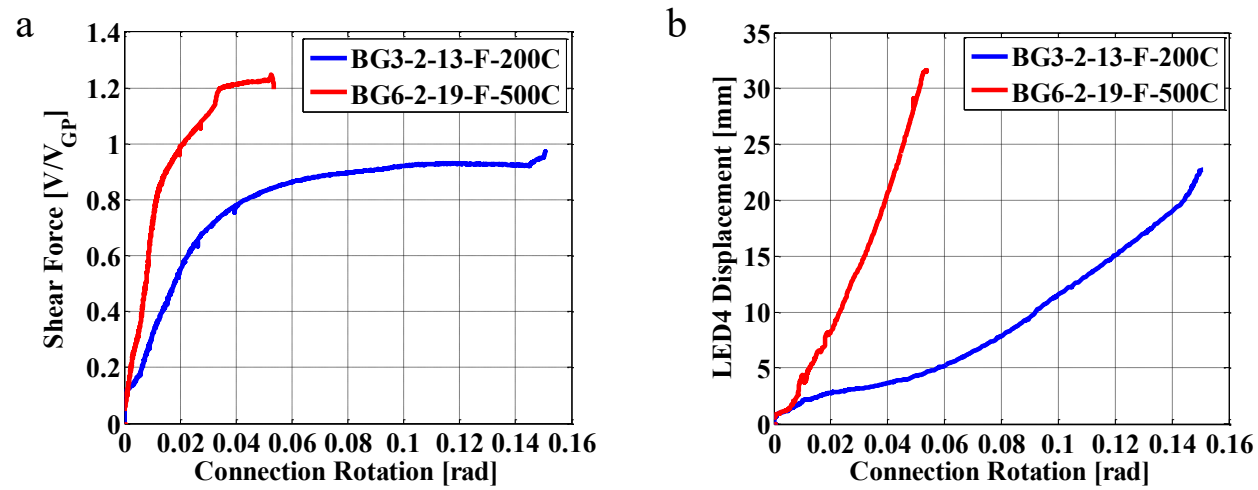

Fig. 7. Measured response vs. connection rotation: (a) connection shear force, (b) shear plate out-of-plane deformation

Referring to Fig. 8a, the axial load was applied to Specimen BG3-2-13-F-200C prior to yielding of the shear tab. Afterward, the extended portion of the shear plate yielded first along its bottom edge (Strain gauge 13 in Fig. 6c) where the compression stress was developed due to the combination of eccentric shear force and the axial compression. Then, plate yielding was observed along the interior bolt line (Strain gauges 14 and 15 in Fig. 6c). The top edge of the shear plate yielded after the bottom because the compression force counterbalanced a portion of the developed 
flexural tensile stress due to the eccentric shear. The connection stiffness reduced at 0.026 rad due to yielding of the extended portion of the shear plate.

The connection shear force still increased and yielding propagated toward the girder web at the upper portion of the stiffener. Strain gauges P6 and P7 indicated that there was flexural yielding due to the eccentric shear force. The stiffener strain gauges, installed adjacent to the girder web, demonstrated the non-uniform distribution of the shear force along the stiffener. Strain gauges P1, $\mathrm{P} 2$ and $\mathrm{P} 3$ depicted the onset and progression of yielding, while the recorded shear strain of strain gauges P4 and P5 was negligible. The connection stiffness was observed to further decrease, as indicated by the change in slope of the curve representing the out-of-plane deformation of the plate bottom edge (LED4, Fig. 6a). However, the connection shear force continued to increase, even though the out-of-plane deformation of the plate grew larger. The shear force attained a plateau (Fig. 8a), which was followed by binding between the side of the shear plate and the side of the beam's web (Fig. 9a), denoted 'side binding' of the web. At this point, indicated by the annotation 'Binding-BW' in Fig. 8a, the shear force of Specimen BG3-2-13-F-200C slightly increased. The test was terminated due to further binding at the beam's bottom flange / stiffener interface (see photograph in Fig. 9a and annotation 'Binding-BF in Fig. 8a). Of note, the ultimate connection strength, as defined by failure of the shear tab, was not reached during the experiments because of this beam binding. Shown in Figs $9 \mathrm{~b}$ to $9 \mathrm{~d}$, the out-of-plane deformation of the shear plate was evident at the end of the test. The two tested specimens behaved in a similar manner under the combined axial and shear force demands. The only practical difference was the post-binding extra strength, which the side binding between the beam thick web and the shear plate in Specimen BG62-19-F-500C had great impact and significantly increased the connection shear force. 
$\mathrm{a}$

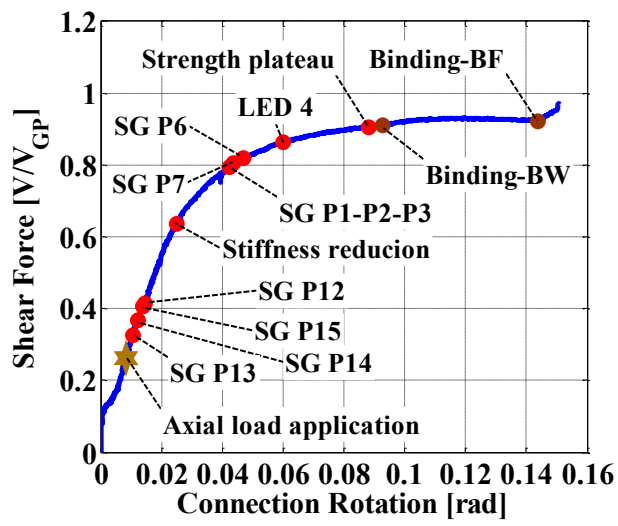

b

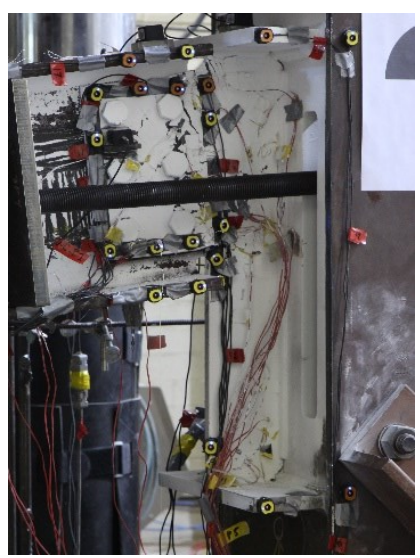

C

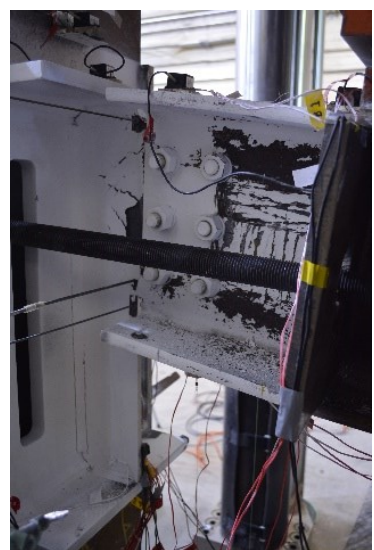

Fig. 8. Specimen BG3-2-13-F-200C: (a) damage propagation (SG: Strain Gauge experienced strain larger than yield strain), (b) deformed shape at strength plataeu (Side 1), (b) deformed shape at strength plataeu (Side 2)
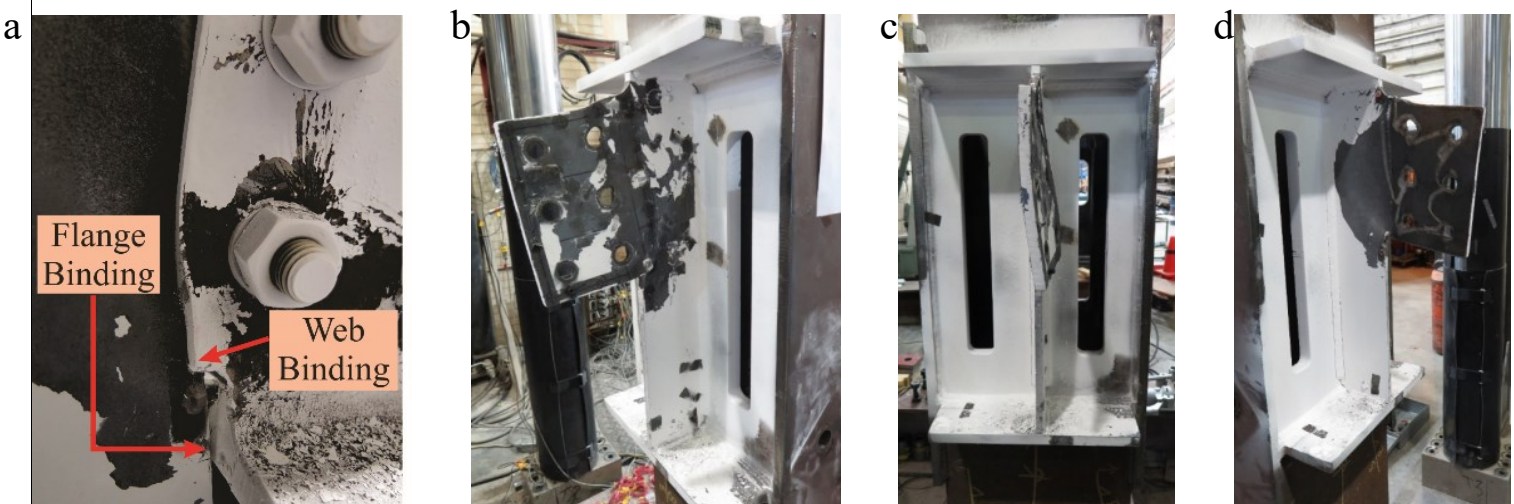

Fig. 9. Specimen BG3-2-13-F-200 : (a) binding between beam and shear plate, (b-d) deformed shape at end of test

Through post-test examination, bearing damage due to contact with the bolts was evident along the interior vertical bolt hole line of both shear plates. Referring to Fig. 10, the bolt hole deformation was larger at the upper portion of the plate where the tensile and shear stress developed simultaneously due to the eccentric shear force.
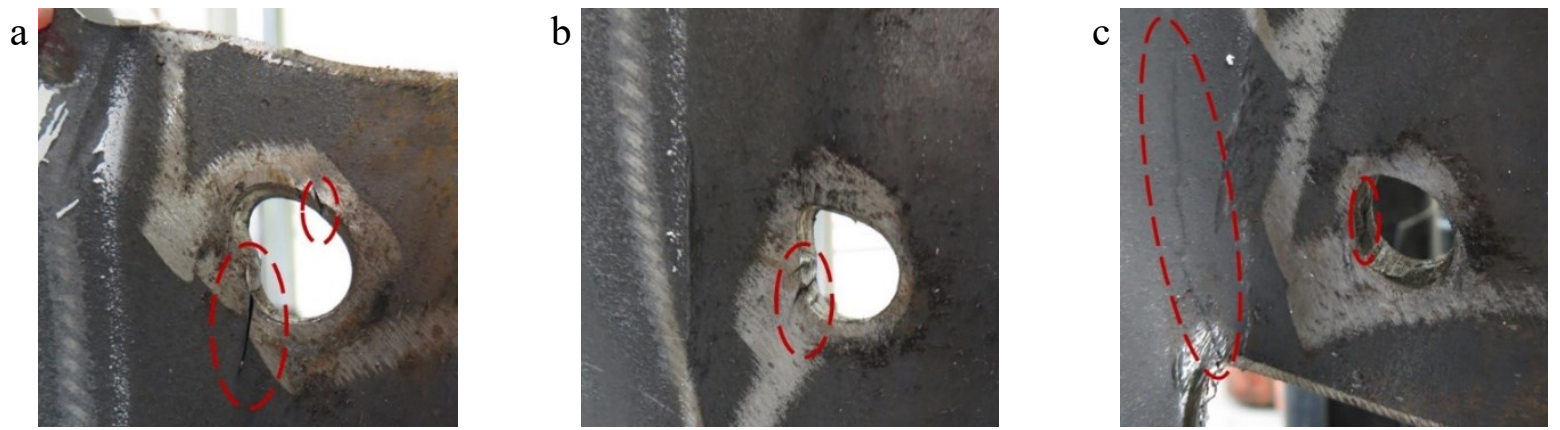

Fig. 10. Bolt hole deformation and fracture along the interior bolt line of specimen BG3-2-13-F-200C at: (a) top bolt hole, (b) middle bolt hole, (c) bottom bolt hole 
In comparison to Specimen BG6-2-19-F-500C (Fig. 11), small fractures and more extensive bearing deformation were observed along the interior bolt holes in Specimen BG3-2-13-F-200C (Fig. 10). After unloading the specimens, a diagonal crack was observed at the bottom re-entrant corner of the shear plate (Figs. 10c and 11c). It is believed that this occurred due to the out-ofplane deformation of the shear plate and binding between the beam web and the shear plate.

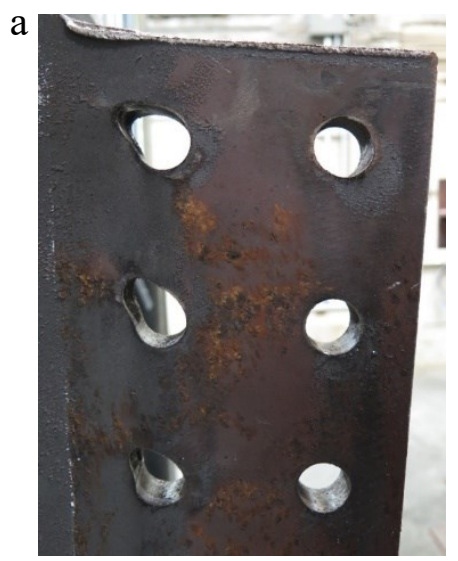

Fig. 11. Specimen BG6-2-19-F-500C:

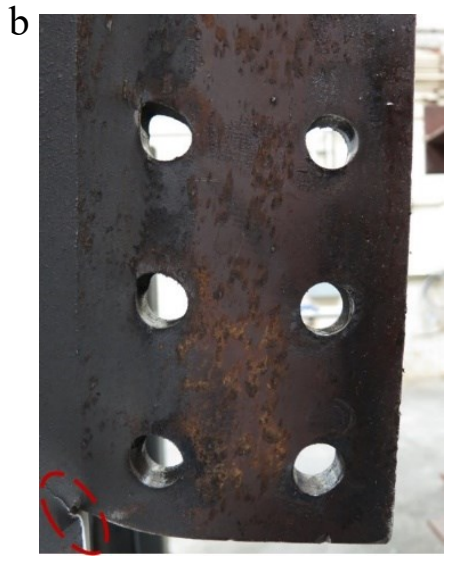

diagonal crack at bottom re-entrant corner

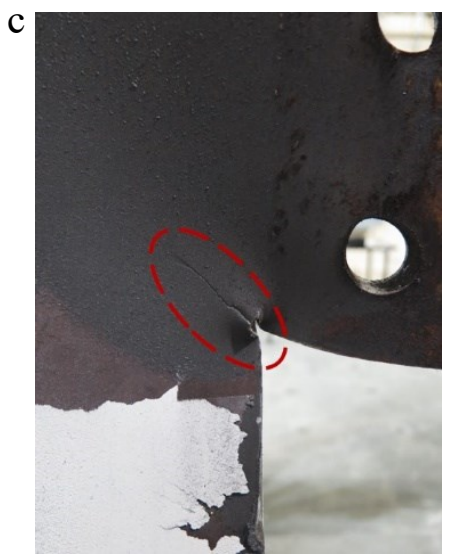

(b) bolt bearing at plate bottom half, (c)

A comparison was carried out of the predictions obtained using the current AISC design procedure for extended shear tab connections with the laboratory observations; albeit this design method was not originally developed for the tested shear tab configuration, no other published method was available. Referring to Table 2, the current design method suggests that bolt shear fracture should be the governing damage state. However, no evidence of bolt deformation leading to fracture was observed through post-test examination of both specimens. The connection stiffness began to decrease at a much larger shear force than the expected resistance corresponding to the flexural and shear yielding of the shear plate. These discrepancies are linked to use of the geometric eccentricity (defined in Fig. 1) in the current AISC design method as the bolt group eccentricity. The complementary CFE simulations (Section 3.2) indicated that the bolt group 
eccentricity was shorter than the $e$ distance because the inflection point formed far from the column face, beyond the bolt group centre.

Although the use of the stabilizer plates significantly increased the connection capacity, the out-of-plane deformation of the shear plate increased rapidly when yielding propagated into the stiffened portion of the plate. It is presumed that this deformation would have been more severe if the shear plate had not satisfied the CSA-S16 compactness requirements [6] for plate girder stiffeners. At this loading step, a reduction of the connection stiffness was also observed. Of note, the out-of-plane deformation occurred because of the combined compression and flexural moment of the shear tab, as demonstrated in subsequent CFE analyses (Section 3).

In addition to the plate yielding, the bolt bearing contributed to the connections' ductility, i.e. the plastic deformation capacity from the onset of yielding to the point where shear strength degradation was identified. Although the bearing deformation was quite large along the interior vertical bolt line of the shear plate, the bearing resistance did not govern the connection's capacity. The connection shear force became larger than the predicted strength corresponding to the net section fracture, while minor tearing around the bolt holes was observed only in Specimen BG32-13-F-200C. This could be attributed to the influence of the compressive force on the connection behaviour, discussed in detail in Sections 4.2 and 4.3, and the inherent conservatism of the design equation for net section fracture. Furthermore, it was not possible to determine the connections' ultimate damage state because binding between the beam web and shear plate changed the load transfer mechanism at the end of the test. Through continuum finite element simulations that excluded the beam binding it was possible to extend the experimental load deformation curve and identify a conceivable ultimate damage state in the shear tab (Section 3).

\section{Complementary continuum finite element simulations}


Continuum finite element (CFE) simulations were conducted to comprehend the load transfer mechanism in stiffened extended shear tab connections subjected to coupled gravity and axial load demands. To expand on the scope of the laboratory experiments, the effect of the axial force direction on the connection response was also studied. Furthermore, CFE simulations were conducted to estimate the ultimate strength of the tested connections in the absence of the beam binding. The CFE models were developed in the commercial software ABAQUS-6.11-3 [34]. The features of the CFE models correspond to the test specimens' geometry, imperfections, boundary conditions, material properties, element size and type, contacts and interactions between connection components, and the imposed loading protocol [10]. Because the initial position of each bolt in its hole could not be controlled in the laboratory tests, the bolts were placed at the centre of the bolt hole in the CFE model, resulting in a $1 \mathrm{~mm}(1 / 32 \mathrm{in}$.) gap around the entire perimeter.

The material properties were defined based on true stress-strain curves of the various components shown in Fig. 12. Other than the bolt's characteristic response, the implemented stress-strain curves were obtained from the testing of tensile coupons. The bolts' material properties were defined based on typical stress-strain curves reported in Kulak et al. [35], which were scaled to meet the minimum specified values for ASTM F3125 Grade A490 bolts [23]. Of note, the constitutive material models of all components were defined up to the ultimate strain.

First-order fully-integrated 3D solid elements (C3D8) were utilized to mesh the various steel components of the respective connections. The element size (Fig. 12) was determined based on a mesh sensitivity analysis. The loading protocol was simulated by applying the displacements of the two actuators, recorded during the tests, to the centerline of the load cubes, while the horizontal $\left(U_{x}\right)$ and out-of-plane $\left(U_{z}\right)$ deformations of the load cubes' centerline were prevented. The lateral 
displacement of the beam flanges at the locations of the lateral braces was restrained. The column's supporting system was replaced by a fixed boundary condition at the column base to increase the computational efficiency of the CFE model. The axial load application system was simulated by applying uniform compression $\left(\mathrm{P}_{\mathrm{x}}\right)$ to the beam's stiffener while it was counterbalanced by applying opposite force to the column.

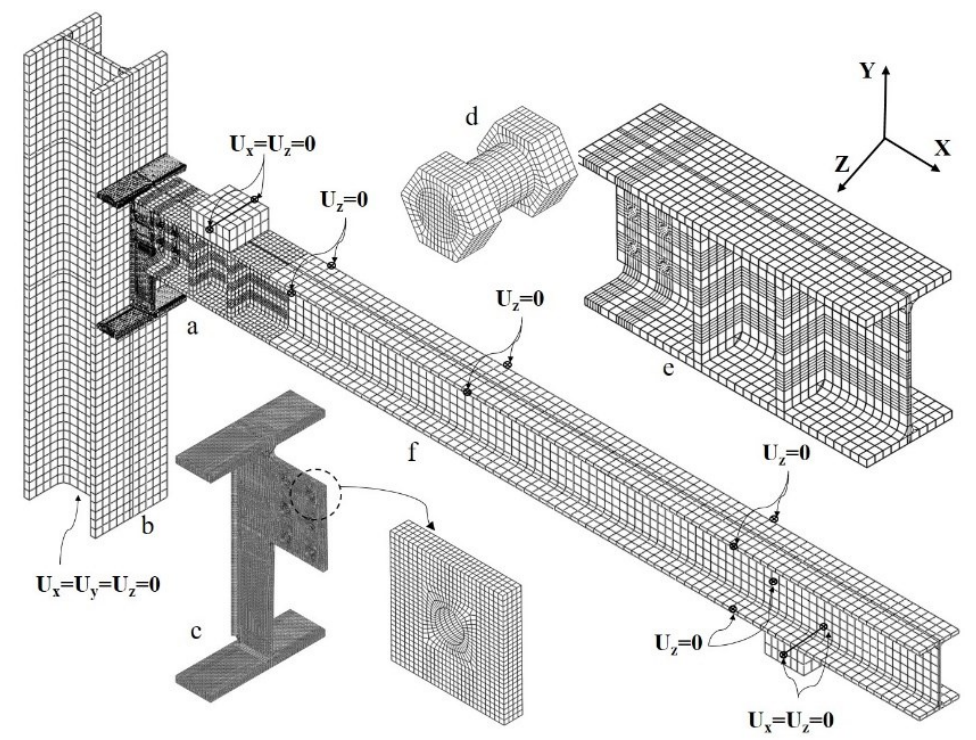

Fig. 12. Continuum finite element model specifics: (a) overall model, (b) column mesh (typical element size of $40 \mathrm{~mm}$ ), (c) shear plate mesh (typical element size of $3 \mathrm{~mm}$ ), (d) bolt mesh (typical element size of $1.5 \mathrm{~mm}$ ), (e) mesh of the beam in the vicinity of connection (typical element size of $20 \mathrm{~mm}$ ), (f) beam mesh (typical element size of $40 \mathrm{~mm}$ )

Frictionless interaction was defined for surface-to-surface contact pairs between the load cubes and the beam flanges. For all other components in contact, surface-to-surface contact pairs with a friction coefficient of 0.3 [1] were used to allow the tangential force transmission. The hard contact formulation, with the capability of separation after closure, was implemented to define the normal behaviour of all contact pairs. Both normal and frictional constraints were enforced by using the penalty method. Instead of an infinite stiffness in the sticking phase of the contact, the penalty method assumed a finite stiffness to decrease the associated computational cost due to convergence issues. In particular, a small slip (elastic slip) can occur between two surfaces even though they 
are in the sticking frictional state. The Abaqus default value for allowable elastic slip is 0.005 of the characteristic contact surface length, which is calculated in each increment. A value for the coefficient of friction (0.30) was chosen based on the AISC 360-16 specification. Furthermore, local instabilities of the shear tab connection were triggered by introducing local imperfections into the shear plate with an analogous shape that was estimated based on the connection bifurcation buckling. These imperfections were then proportioned to the limits of manufacturing tolerances for the web and flange of W-sections [36-38]. This approach has been successfully implemented in prior CFE studies concerned with member and local instabilities [39]. Additional details of the CFE model simulations can be found in [10].

\subsection{Model validation}

To evaluate the accuracy of the numerical analyses, the results obtained from the CFE models were compared with the measured responses for each specimen, as shown in Fig. 13. The developed connection shear force and the out-of-plane deformation of the shear plate were chosen as the CFE model verification criteria.
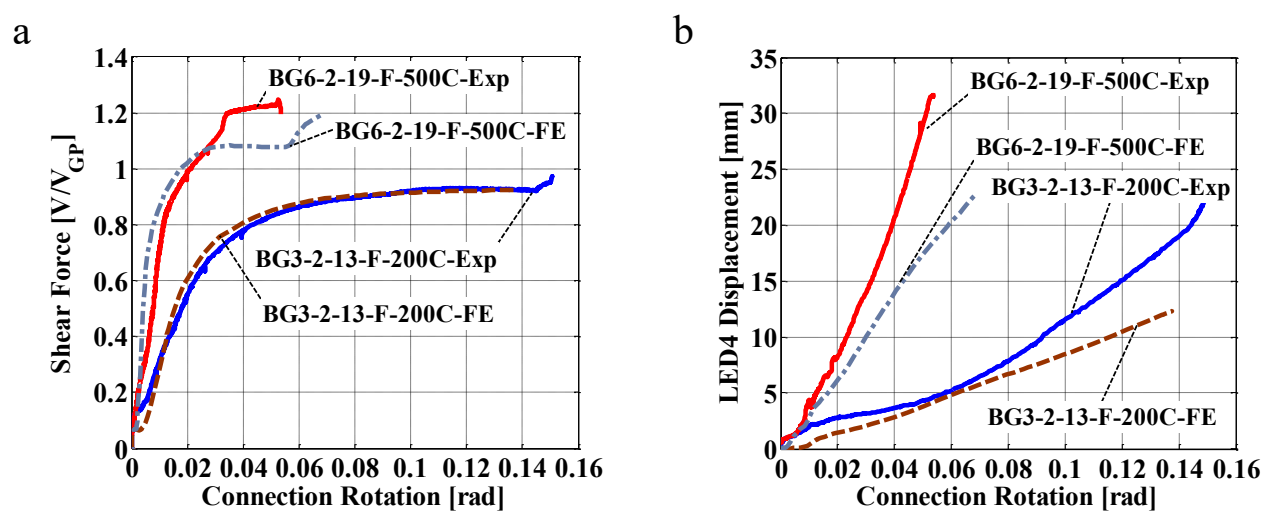

Fig. 13. CFE model verification: (a) shear force, (b) shear plate out-of-plane deformation

Referring to Fig. 13, the CFE model predicted reasonably well the connection response up to binding at beam web / stiffener interface. The side binding between the beam web and the stiffened 
portion of the shear plate (Fig. 9a) occurred prior to beam flange binding. This side binding significantly increased the connection shear force in Specimen BG6-2-16-F-500C, while there were minor effects on Specimen BG3-2-13-F-200C (Fig. 13a). This discrepancy was due to the uncertainties related to the contact between the beam web's bottom edge and the shear plate. Fabrication tolerances, installation procedure along with the magnitude of imperfections introduced to the CFE model are other contributors to these uncertainties.

As a snug-tightened shear tab connection, its initial response depended greatly on the contact between shanks of the bolts and the bolt holes. As mentioned before, each bolt was placed conservatively at the centre of its bolt hole in the CFE model; the initial contact conditions of the bolts in the laboratory test specimens may have been different from those assumed for the CFE model. Due to this discrepancy, the predictions of the connection shear force obtained from the CFE models deviated from the test measurements in the initial increments of the applied loading.

\subsection{Simulation results}

Figures 14 and 15 show the normalized predictions of the CFE models. Referring to Figs. 14a and $15 \mathrm{a}$, the shear force along the outer end of the shear plate's re-entrant corners was normalized based on the plastic shear resistance of the gross section $\left(\mathrm{V}_{\mathrm{GP}}=0.6 \mathrm{~F}_{\mathrm{y}} \mathrm{A}_{\mathrm{g}}\right)$, while the plate's plastic shear resistance of the net section $\left(\mathrm{V}_{\mathrm{NP}}=0.6 \mathrm{~F}_{\mathrm{y}} \mathrm{A}_{\text {net }}\right)$ was implemented to normalize the shear force along the bolt line (Figs. 14b and 15b). The plastic bending moment resistance of the gross section $\left(\mathrm{M}_{\mathrm{GP}}=\mathrm{F}_{\mathrm{y}} \mathrm{Z}_{\mathrm{g}}\right)$ was used to normalize the bending moment at the plate's gross section, as shown in Figs. $14 \mathrm{c}$ and $15 \mathrm{c}$. The bending moment along the plate's interior bolt line (Figs. 14d and 15d) was normalized based on the flexural resistance of the plate's net section $\left(\mathrm{M}_{\mathrm{NP}}=\mathrm{F}_{\mathrm{y}} \mathrm{Z}_{\text {net }}\right)$. The plastic

section modulus was defined for an odd number of bolt rows as $Z_{n e t}=1 / 4 t_{p l}\left(s-d_{h}\right)\left(n^{2} s+d_{h}\right)$, while 
$Z_{\text {net }}=1 / 4 t_{p l}\left(s-d_{h}\right)\left(n^{2} s\right)$ was used for an even number of bolt rows [40]. In these equations, $\mathrm{n}=$ number of rows of bolts, $\mathrm{s}=$ bolt spacing, $\mathrm{d}_{\mathrm{h}}=$ diameter of bolt hole, $\mathrm{t}_{\mathrm{pl}}=$ plate thickness, and $\mathrm{d}_{\mathrm{pl}}=$ plate depth. The aforementioned plastic resistances of the shear plate, shown in Table 3, were calculated based on its measured dimensions and yield stress.

\begin{tabular}{lcc}
\multicolumn{4}{c}{ Table 3. Calculated plastic capacities of shear tab test specimens } \\
\hline Specimens & BG3-2-13-F & BG6-2-19-F \\
\hline $\mathrm{P}_{\mathrm{GP}}\left(\mathrm{F}_{\mathrm{y}} \mathrm{A}_{\mathrm{g}}=\mathrm{F}_{\mathrm{y}} \mathrm{d}_{\mathrm{pl}} \mathrm{t}_{\mathrm{pl}}\right)$ & $1268 \mathrm{kN}$ & $3294 \mathrm{kN}$ \\
$\mathrm{P}_{\mathrm{NP}}\left(\mathrm{F}_{\mathrm{y}} \mathrm{A}_{\mathrm{net}}=\mathrm{F}_{\mathrm{y}}\left(\mathrm{d}_{\mathrm{pl}}-\mathrm{nd}_{\mathrm{h}}\right) \mathrm{t}_{\mathrm{pl}}\right)$ & $950 \mathrm{kN}$ & $2331 \mathrm{kN}$ \\
$\mathrm{V}_{\mathrm{GP}}\left(0.6 \mathrm{~F}_{\mathrm{y}} \mathrm{A}_{\mathrm{g}}=0.6 \mathrm{~F}_{\mathrm{y}} \mathrm{d}_{\mathrm{pl}} \mathrm{t}_{\mathrm{pl}}\right)$ & $761 \mathrm{kN}$ & $1976 \mathrm{kN}$ \\
$\mathrm{V}_{\mathrm{NP}}\left(0.6 \mathrm{~F}_{\mathrm{y}} \mathrm{A}_{\mathrm{net}}=0.6 \mathrm{~F}_{\mathrm{y}}\left(\mathrm{d}_{\mathrm{pl}}-\mathrm{nd}_{\mathrm{h}}\right) \mathrm{t}_{\mathrm{pl}}\right)$ & $570 \mathrm{kN}$ & $1398 \mathrm{kN}$ \\
$\mathrm{M}_{\mathrm{GP}}\left(\mathrm{F}_{\mathrm{y}} \mathrm{Z}_{\mathrm{g}}=\mathrm{F}_{\mathrm{y}} \mathrm{t}_{\mathrm{pl}} \mathrm{d}_{\mathrm{pl}}^{2} / 4\right)$ & $72.5 \mathrm{kN} \cdot \mathrm{m}$ & $376.5 \mathrm{kN} . \mathrm{m}$ \\
$\mathrm{M}_{\mathrm{NP}}\left(\mathrm{F}_{\mathrm{y}} \mathrm{Z}_{\mathrm{net}}\right)$ & $54.0 \mathrm{kN} \cdot \mathrm{m}$ & $256.8 \mathrm{kN} . \mathrm{m}$ \\
\hline
\end{tabular}

Regarding Specimen BG3-2-13-F-200C, a comparison between the normalized shear force and the connection rotation (Figs. 14a and 14b) demonstrates that only a fraction of the connection shear force was transferred through the net section along the centerline of the bolt holes, i.e. the critical section with the smallest cross-sectional area along the plate. Referring to Fig. 14a, Specimen BG3-2-13-F-200C experienced a connection shear force equal to $614 \mathrm{kN}\left(\mathrm{V} / \mathrm{V}_{\mathrm{GP}}=0.81\right)$ at $0.04 \mathrm{rad}$ rotation, while the net section was only subjected to a shear force of $463 \mathrm{kN}\left(\mathrm{V}_{\mathrm{n}} / \mathrm{V}_{\mathrm{NP}}\right.$ $=0.81$ in Fig. 14b). Figures 15a and 15b show a similar trend for Specimen BG6-2-19-F-500C. This observation, which coincided with prior research studies [41], was due to the bearing mechanism between the bolt shanks and the bolt holes, which is further elaborated in Section 4.2. A larger bending moment developed at the gross section (Figs. 14c and 15c) in comparison to the net section (Figs. 14d and 15d) because the inflection point (Figs. 14e and 15e) formed far from the column face, away from the centroid of the bolt group. 

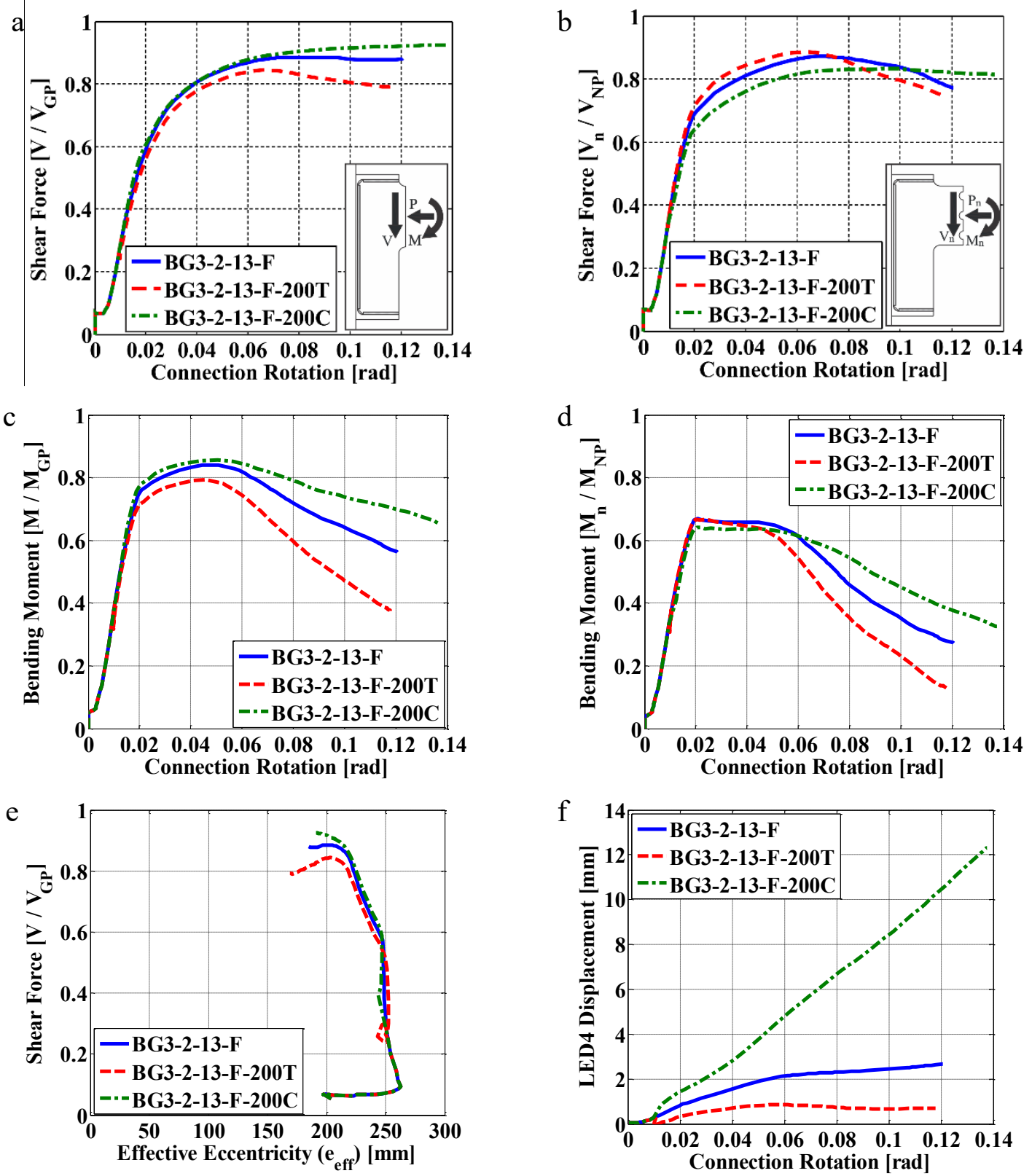

Fig. 14. Simulated response of Specimen BG3-2-13-F: (a) connection shear force, (b) net section shear force, (c) gross section bending moment, (d) net section bending moment, (e) effective eccentricity, (f) plate out-of-plane deformation 

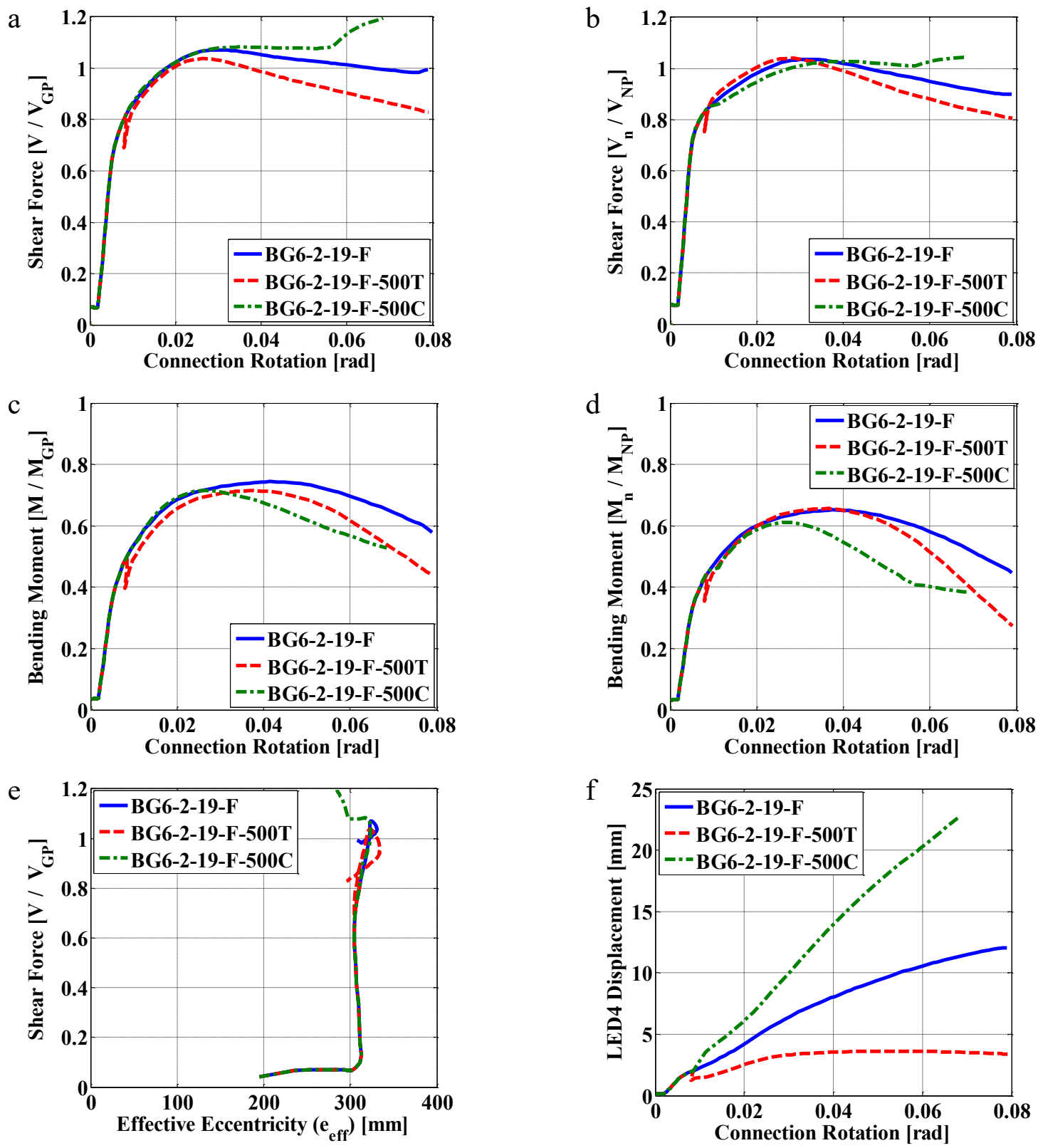

Fig. 15. Simulated response of Specimen BG6-2-19-F: (a) connection shear force, (b) net section shear force, (c)gross section bending moment, (d) net section bending moment, (e) effective eccentricity, (f) plate out-of-plane deformation

To evaluate the influence of the axial load on the observed connection behaviour and associated damage states, supplemental CFE analyses were carried out for each specimen. Only gravity-induced shear force was applied to the connection in the first CFE analysis (models BG32-13-F and BG6-2-16-F). The connection was subjected to combined tensile and shear forces in 
the second CFE analysis. To retain simplicity in the analysis, the tensile force was set equal to the magnitude of the compressive load used during testing (BG3-2-13-F-200T and BG6-2-16-F$500 \mathrm{~T})$.

In all the CFE models, gross and net section yielding of the shear plate were observed and the net section fracture along the plate interior bolt line was determined as the connection's ultimate damage state. Of note, the capability of this simulation procedure to capture the net section fracture was verified. The developed CFE models replicated accurately the ultimate strength of unstiffened extended shear tabs that ultimately failed due to net section fracture. The details and verification of this simulation procedure can be found in [42]. Referring to Figs. 14 and 15, the axial force affected the connection's response slightly because the applied axial load magnitude was small $\left(\mathrm{P} / \mathrm{P}_{\mathrm{GY}}=0.16\right.$ and 0.15 for Specimens BG3-2-13-F and BG6-2-19-F, respectively).

\section{Discussion}

\subsection{Shear plate yielding}

Referring to Fig. 16, Neal's interaction equation [43] was used to account for the interaction of axial, shear, and flexural demands at the plate's gross and net sections. The interaction equations specified by the AISC [2] and Neal [43], Eqs. (3) and (4), respectively, provide similar predictions for the cases examined as part of this study. Astaneh [44] proposed Eq. (4) as a simplified version of Neal's interaction equation, which was later incorporated into the AISC Steel Construction Manual [2] for the rectangular connecting element under in-plane loading. Equations (2), (3), and (4) were all conservative, while Eq. (2) resulted in the most conservative predictions for the connection resistance corresponding to the yielding of the gross section. 


$$
\begin{gathered}
\left(\frac{M}{M_{P}}\right)+\left(\frac{P}{P_{P}}\right)^{2}+\left(\frac{\left(V / V_{P}\right)^{4}}{1-\left(P / P_{P}\right)^{2}}\right) \leq 1 \\
\left(\frac{M}{M_{P}}\right)+\left(\frac{P}{P_{P}}\right)^{2}+\left(\frac{V}{V_{P}}\right)^{4} \leq 1
\end{gathered}
$$

a

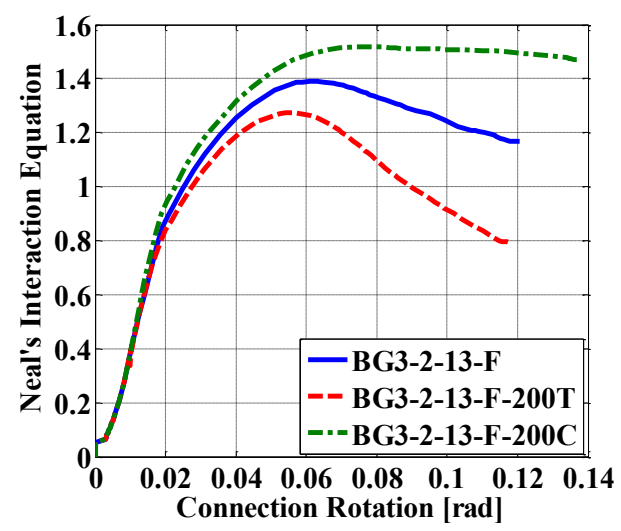

$\mathrm{C}$

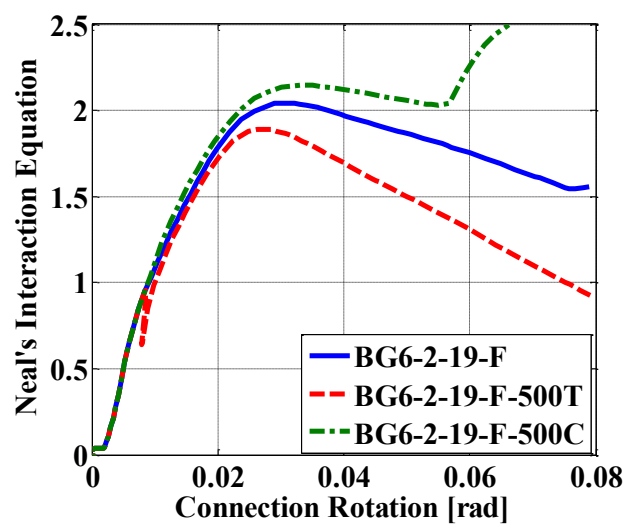

b

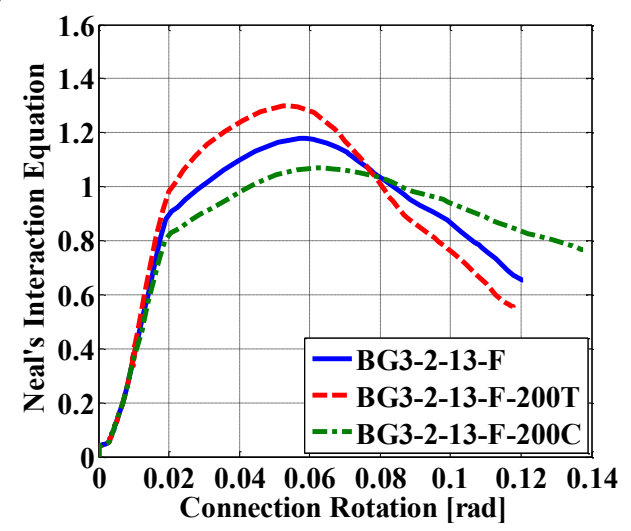

d

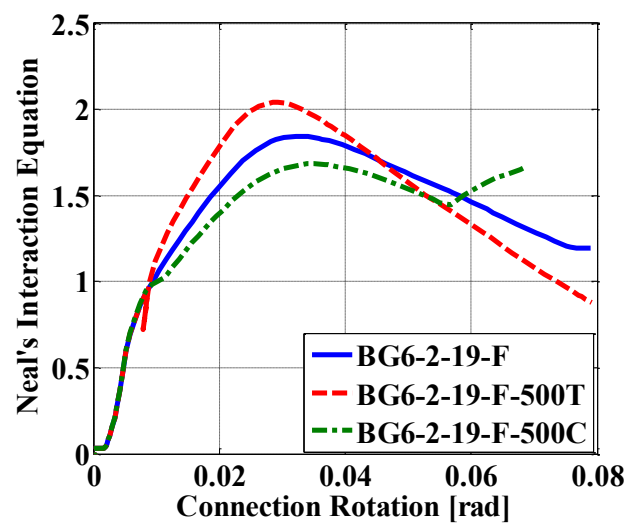

Fig. 16. Neal's Interaction equation (Eq. (3)) at: (a and b) gross and net sections of Specimen BG3-2-13-F, respectively, (c and d) gross and net sections of Specimen BG6-2-19-F, respectively

The CFE models of connections BG3-2-13-F-200C and BG6-2-19-F-500C behaved in a similar manner to the test specimens. Yielding began from the re-entrant corners of the shear plate, then propagated toward the interior bolt line. The CFE models indicated that the connection stiffness slightly decreased when a large portion of the shear plate along the interior bolt line yielded. The full depth of the shear plate along the net section yielded after yielding of the gross section of connection BG3-2-13-F-200C, while they occurred at the same time for connection 
BG6-2-19-F-500C. Following the yielding of the shear plate, its out-of-plane deformation increased. Referring to Fig. 17, the CFE models demonstrated that the maximum equivalent plastic strain (PEEQ) developed at the bottom re-entrant corner and at the bolt holes of the plate's upper portion. This PEEQ pattern, representative of the net section fracture, concluded that this damage state would determine the connection's ultimate strength in the absence of beam binding.

a

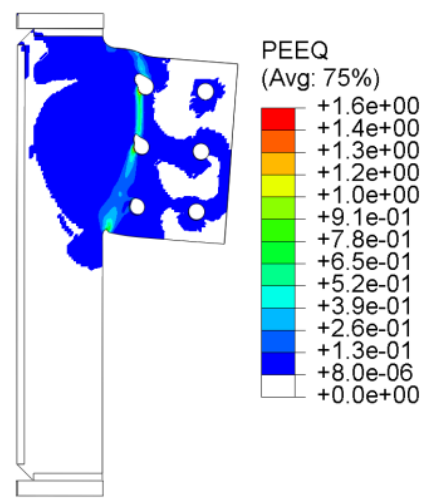

b

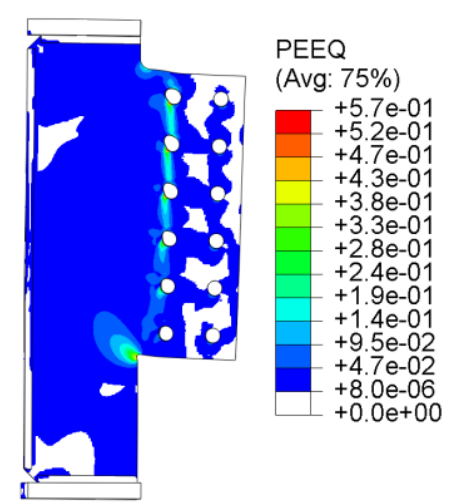

Fig. 17. Shear plate equivalent plastic strain (PEEQ) corresponding to the net section fracture at: (a) BG3-2-113-F-200C, (b) BG6-2-1-9-F-500C

\subsection{Shear plate internal forces along the interior bolt line}

Referring to Table 3, the plate's plastic shear resistance at the net section is a fraction $\left(A_{\text {net }} / A_{g}\right)$ of its plastic shear resistance at the gross section. However, Figs. 14(a \& b) and 15(a \& b) show that the $\mathrm{V} / \mathrm{V}_{\mathrm{GP}}$ ratio was larger than $\mathrm{V}_{\mathrm{n}} / \mathrm{V}_{\mathrm{NP}}$. This observation demonstrates that the section along the bolt line centerline (net section) was subjected to only a portion of the connection shear force. Furthermore, applying the axial force changed the shear demand at the net section (Figs. 14b \& 15b). To clarify this observation, the net section's shear and axial forces $\left(V_{n}\right.$ and $P_{n}$ in Fig $14 b$, respectively) were compared with corresponding values from the gross section of the plate (Fig. 18). Referring to Figs. 18a and 18b, the tensile force increased the ratio between the shear force at the net and gross sections, while the compression force decreased it. Referring to Figs. 18c and $18 \mathrm{~d}$, the axial force along the net section was compared with the magnitude of the applied axial 
force $\left(\mathrm{P}_{\mathrm{a}}\right), 200 \mathrm{kN}$ and $500 \mathrm{kN}$ for connections BG3-2-13-F and BG6-2-19-F, respectively. In comparison to the tensile force, the net section was subjected to a smaller portion of the applied axial force in the presence of the compression force. Furthermore, Figs. $18 \mathrm{c}$ and $18 \mathrm{~d}$ show that the tensile force was developed along the net section even under gravity-induced shear force.

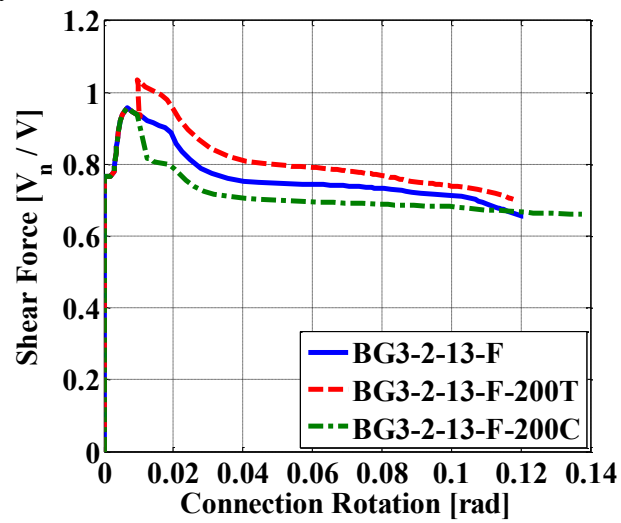

C

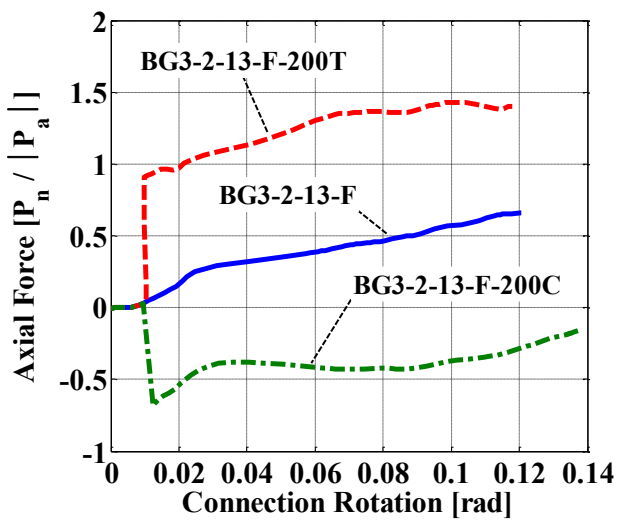

$\mathrm{b}$

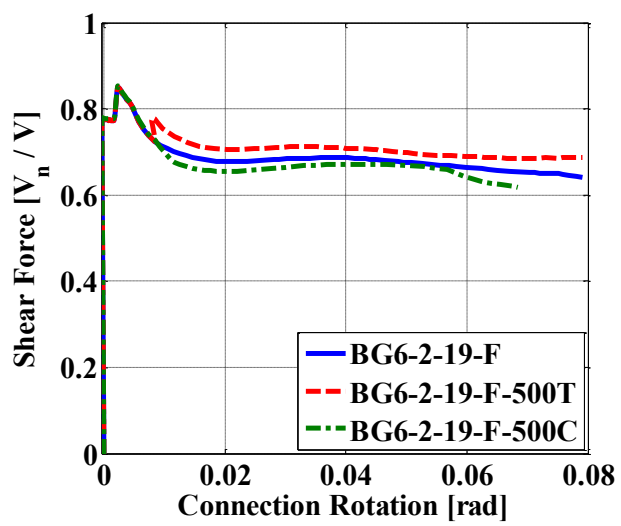

d

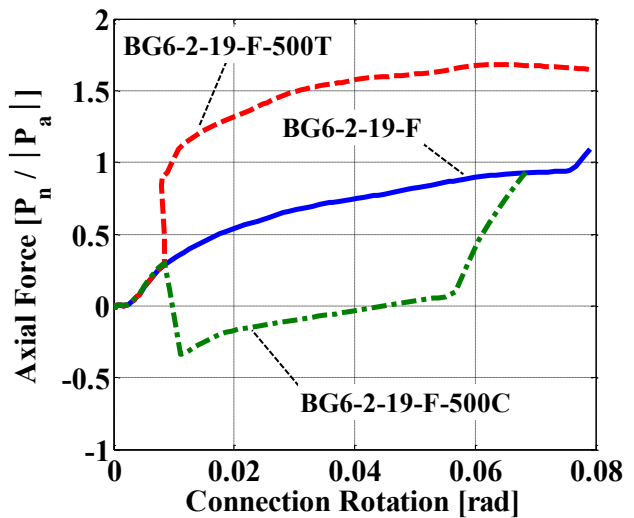

Fig. 18. CFE model predictions for: (a) shear force of BG3-2-13-F models, (b) shear force of BG6-2-19-F models, (c) Axial force of BG3-2-13-F models,(d) Axial force of BG6-2-19-F models $\left(\left|\mathrm{P}_{\mathrm{a}}\right|\right.$ is the magnitude of the applied axial force, $200 \mathrm{kN}$ and $500 \mathrm{kN}$ for connections BG3-2-13-F and BG6-2-19-F, respectively; $\mathrm{P}_{\mathrm{n}}$ and $\mathrm{V}_{\mathrm{n}}$ stand for the axial and shear demands along the plate net section, respectively)

The bearing mechanism between the bolt shanks and the bolt holes was further studied to explain the reasons for the aforementioned observations. Figure 19a shows the bolt group, which was subjected to the eccentric shear force. In addition to the vertical shear force, a horizontal force was developed in the top and bottom bolts due to the eccentric shear force and its consequent 
bending moment. Referring to Fig 19b, the horizontal force moved the top bolt away from the centerline of the bolt hole, while the bottom bolt moved closer to the support.

a

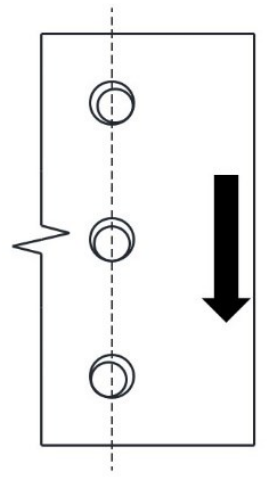

b

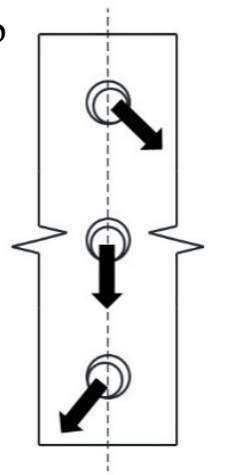

$\mathrm{c}$

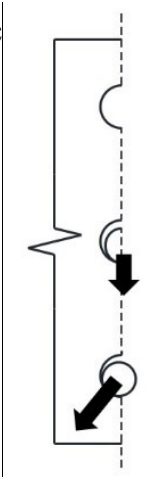

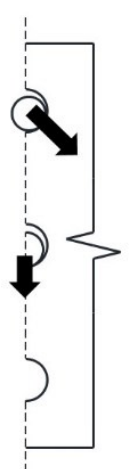

Fig. 19. Bolt group under an eccentric shear force, (a) applied shear force, (b) resultant force at each bolt due to the applied eccentric shear force, (c) the distribution of the resultant force along the bolt line centerline

The middle bolt (Fig. 20a) transferred a vertical shear force to the plate while it was placed along the centerline of the bolt hole. Therefore, half of the bolts' shear force was transferred through the net section. In the presence of the tensile force (the top bolt), the net section was subjected to a larger portion of the shear and axial forces as the bolt moved away from the support and crossed the bolt line centerline (Fig. 20b). Therefore, the horizontal force of the top bolt subjected the net section to the tensile force (Fig. 19c). That was the reason behind development of an additional tension in Figs. 18c and 18d. In contrast, an applied axial compression force pushed the bottom bolt toward the support (Fig. 20c) and the net section resisted a smaller component of the shear and axial force. 

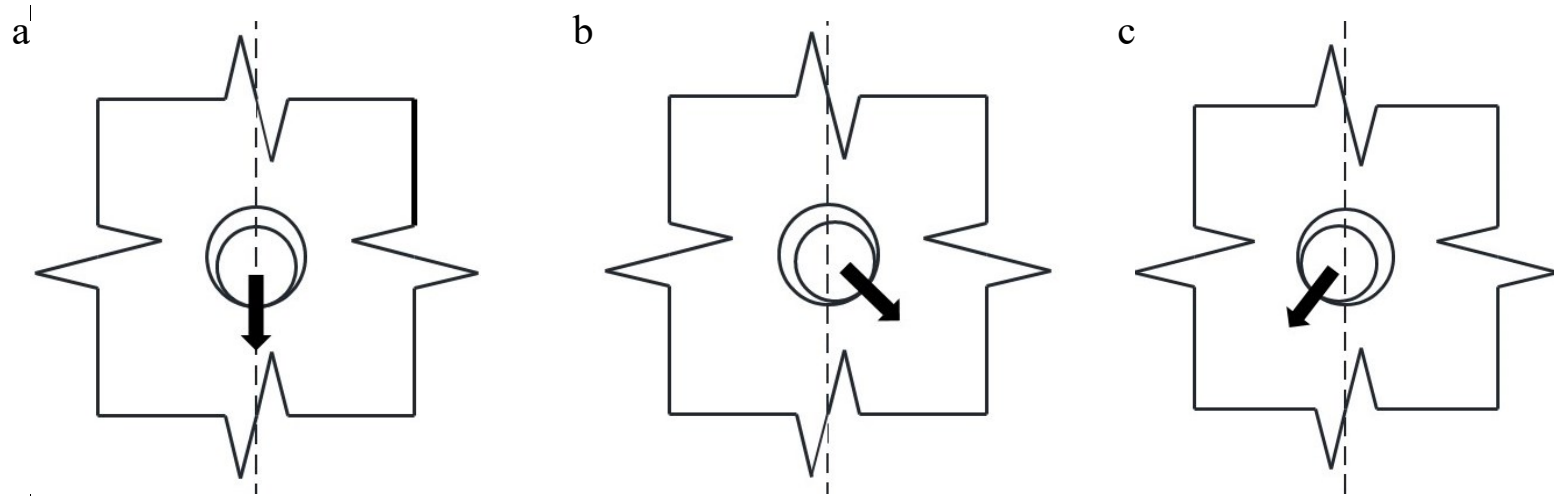

Fig. 20. Bolt under: (a) shear force, (b) shear and tension, (c) shear and compression

\subsection{Effect of axial force}

Referring to Figs. 14a and 15a, the axial tensile force decreased the ultimate shear resistance of the connection, while the axial compressive force increased it. This occurred because the tensile force increased the force demands on the interior bolt line of the shear plate, while the compressive force decreased those demands (Figs. 14b and 15b). Then, the tensile force hastened the onset of the connection's ultimate damage state, i.e. net section fracture of the shear plate, while the axial compressive force delayed the onset of this damage state. The same observations hold true for the connection resistance corresponding to the net section yielding. Referring to Table 4, the tensile force caused the net section yielding to precede the gross section yielding. However, the difference between the yielding strength of the net and gross sections was small; hence, the connection could still resist much larger shear after the gross section yielding. In addition to the axial force, the ratio between the gross and net section areas affected the yielding sequence of the gross and net sections. In model BG3-2-13-F, the net section yielded shortly after the gross section, while they occurred at the same time in the BG6-2-19-F model. The aforementioned ratio, $\mathrm{A}_{\text {net }} / \mathrm{A}_{\mathrm{g}}$, was equal to 0.73 and 0.69 for Specimens BG3-2-13-F and BG6-2-19-F, respectively. 
Table 4. CFE model predictions for connection resistance

\begin{tabular}{|c|c|c|c|c|c|c|}
\hline \multirow[b]{2}{*}{ Axial Load } & \multicolumn{3}{|c|}{ BG3-2-13-F } & \multicolumn{3}{|c|}{ BG6-2-19-F } \\
\hline & $200 \mathrm{C}$ & 0 & $200 \mathrm{~T}$ & $500 \mathrm{C}$ & 0 & $500 \mathrm{~T}$ \\
\hline Damage state & $\begin{array}{l}\text { Measured } \\
\text { strength } \\
(\mathrm{kN})\end{array}$ & $\begin{array}{l}\text { Measured } \\
\text { strength } \\
(\mathrm{kN})\end{array}$ & $\begin{array}{l}\text { Measured } \\
\text { strength } \\
(\mathrm{kN})\end{array}$ & $\begin{array}{l}\text { Measured } \\
\text { strength } \\
(\mathrm{kN})\end{array}$ & $\begin{array}{l}\text { Measured } \\
\text { strength } \\
(\mathrm{kN})\end{array}$ & $\begin{array}{c}\text { Measured } \\
\text { strength } \\
(\mathrm{kN})\end{array}$ \\
\hline Gross section yielding & 507 & 518 & 517 & 1674 & 1676 & 1631 \\
\hline Net section yielding & 631 & 545 & 450 & 1767 & 1676 & 1544 \\
\hline Out-of-plane deformation & 662 & --- & --- & 1995 & 2021 & --- \\
\hline Net section fracture & 688 & 666 & 634 & 2120 & 2103 & 2046 \\
\hline
\end{tabular}

Referring to Figs $14 \mathrm{f}$ and $15 f$, the axial compressive force increased the out-of-plane deformation of the plate, while the tensile force decreased it. This observation suggested that the compression could trigger the shear plate buckling and alter the connection's ultimate damage state, especially if a slender shear plate would have been used or a larger compressive force was applied.

\subsection{Evaluation of the current design procedure of extended shear tab connections}

Various damage states were observed in the studied connection configurations, including the gross and net section yielding of the shear plate, the shear plate out-of-plane deformation, and the net section fracture. Of note, the shear plate yielded at its gross and net sections because of the interaction of moment, shear and axial force. Referring to Table 5, the results obtained with the current AISC design method [2] were directly compared with those obtained from the laboratory measurements and the CFE simulations. The accuracy of the design method improved if the geometric eccentricity was replaced with the measured eccentricity corresponding to the gross section yielding of the shear plate. Furthermore, the current design method reliably predicted the governing damage state when the measured eccentricity was implemented. Of note, the AISC design method [2] allows for the design of the bolt group based on an alternative eccentricity, 
obtained from a rational procedure. In this case, the supporting member should be designed for the effect of shear force at the same alternative eccentricity.

Table 5. Connection resistance corresponding to possible damage states

\begin{tabular}{|c|c|c|c|c|c|c|}
\hline & \multicolumn{3}{|c|}{ BG3-2-13-F-200C } & \multicolumn{3}{|c|}{ BG6-2-19-F-500C } \\
\hline Damage state & $\begin{array}{l}\text { Expected } \\
\text { strength }^{1} \\
(\mathrm{kN})\end{array}$ & $\begin{array}{l}\text { Expected } \\
\text { strength }^{2} \\
(\mathrm{kN})\end{array}$ & $\begin{array}{l}\text { Measured } \\
\text { strength } \\
(\mathrm{kN})\end{array}$ & $\begin{array}{c}\text { Expected } \\
\text { strength }^{1} \\
(\mathrm{kN})\end{array}$ & $\begin{array}{l}\text { Expected } \\
\text { strength }^{2} \\
(\mathrm{kN})\end{array}$ & $\begin{array}{c}\text { Measured } \\
\text { strength } \\
(\mathrm{kN})\end{array}$ \\
\hline Plate moment-shear-axial force yielding & 365 & $452^{3}$ & 507 & 1171 & $1621^{3}$ & 1674 \\
\hline Plate Shear yielding & 761 & 761 & -- & 1976 & 1976 & 1976 \\
\hline Bolt bearing & 367 & 965 & $--^{3}$ & 1725 & 4204 & $--^{3}$ \\
\hline Plate flexural buckling & 456 & $625^{4}$ & $662^{5}$ & 1616 & $2885^{4}$ & $1995^{5}$ \\
\hline Shear rupture at net section of shear plate & 648 & 648 & 687 & 1824 & 1824 & 2120 \\
\hline Bolt shear & 327 & 858 & $>687$ & 1105 & 2743 & $>2120$ \\
\hline Weld tearing & 2544 & $2334^{6}$ & -- & 4505 & $4777^{6}$ & -- \\
\hline
\end{tabular}

\footnotetext{
${ }^{1}$ Expected strength based on geometric eccentricity (e)

${ }^{2}$ Expected strength based on measured eccentricity

${ }^{3}$ Although large bearing deformation was observed, bearing failure did not occur

${ }^{4}$ Flexural buckling strength of the extended portion of the shear plate

${ }^{5}$ Shear resistance corresponding to the shear plate out-of-plane deformation

${ }^{6}$ Strength of C-shape weld group
}

Referring to Table 5, Eq. (2) resulted in a conservative estimate of the moment-shear-axial force yielding of the shear plate gross section. This prediction could be improved if Eqs. (3) and (4) were instead used. Based on these equations, the shear plate gross section of connections BG32-13-F-200C and BG6-2-19-F-500C yielded at a connection shear force equal to $496 \mathrm{kN}$ and 1642 $\mathrm{kN}$, respectively. Furthermore, the current design procedure may significantly overestimate the buckling strength of connection BG6-2-19-F-500C, because it neglects the detrimental effects of the axial and shear forces on the plate's flexural capacity. To address this issue, Dowswell \& Whyte [28] used Eq. (3) to determine the available flexural buckling strength in the presence of the shear and axial forces. If their advice were taken for the test specimens, the buckling strength of the extended portion of the shear plate would be equal to the applied force corresponding to the gross section yielding of the shear plate. Notably, the $15^{\text {th }}$ edition of the AISC Steel Construction 
Manual [2] introduced the simplified form of Neal's interaction equation (Eq. (4)) to consider the interaction of in-plane loads for a rectangular connecting plate. To calculate the weld group capacity under an eccentric shear force, the Instantaneous Centre of Rotation (ICR) method was implemented for the C-Shape weld group, while only the vertical weld lines were considered in the calculation of the weld group capacity under a concentric shear force.

Among the observed damage states, the gross section yielding of the shear plate occurred earlier under a smaller shear force. Furthermore, other damage states occurred when the connection underwent large deformation and rotation, which negatively affected the supported beam's serviceability. Therefore, the moment-shear-axial force yielding of the shear plate's gross section should be considered as a conservative estimate of the connection's capacity. In the presence of the axial tensile force, yielding of the net section preceded yielding of the gross section (i.e. BG32-13-F-200T and BG6-2-19-F-500T). However, the yield strength of the gross section was still a conservative estimate of the connection's capacity because the difference between the yield strength of the gross and net sections was small and the connection was able to resist a much larger shear force.

\section{Conclusions}

Two full-scale specimens were tested to comprehend the behaviour of the double-sided configuration of the full-depth extended beam-to-girder shear tab connection under coupled gravity and axial force demands. The test specimens comprised different features, including shear plate dimensions, bolt size, bolt group configuration, geometric eccentricity, beam and girder sizes. Furthermore, continuum finite element models, which were validated up to web binding, were utilized to investigate the dependency of the connection's behaviour on critical parameters 
including the axial force direction and the force distribution along the plate net section. The main findings of the paper are summarized as follows:

- The double-sided configuration of the full-depth extended beam-to-girder shear tab yielded through its net section along the bolt line, the closest to the girder. Furthermore, the gross section yielding of the shear plate occurred along the outer end of its re-entrant corners.

- The net section fracture was determined as the ultimate damage state of the studied connections.

- The net section along the centerline of the plate's interior bolt line was subjected to a portion of the connection axial and shear forces. This amount depended on the number of vertical bolt lines, bolt hole diameter, the distance between bolt holes, the axial load direction and magnitude, and the initial position of the bolt in its hole.

- The compressive axial load increased the out-of-plane deformation of the shear plate, which could result in its buckling if a larger compressive force were applied. The axial compressive force decreased the shear force demand on the net section.

- The tensile axial force accelerated the plate yielding and fracture along the interior bolt line by increasing the force demands on the shear plate's net section. Furthermore, the tensile force decreased the shear plate's out-of-plane deformation and delayed the plate buckling.

- The shear plate's gross section yielding strength could be considered as a conservative estimate of the connection's resistance since a much larger shear force can be sustained following the gross section yielding of the shear plate. Supplemental analyses should be conducted to validate this observation in the presence of large axial forces.

- The current AISC design method underestimated the connection shear capacity corresponding to the plate flexural-shear-axial force yielding of Specimens BG3-2-13-F-200C and BG6-2- 
$19-\mathrm{F}-500 \mathrm{C}$ by $28 \%$ and $30 \%$, respectively. This could be attributed to the AISC's assumption that the inflection point formed at the girder web's face while the inflection point formed far away from the girder web, beyond the bolt group centroid.

To provide definitive recommendations for the design of stiffened extended shear tab connections, a parametric finite element study is needed to relate the observations described herein for a wider range of such connections. This work is ongoing.

\section{Acknowledgments}

The authors would like to thank the ADF Group Inc. and DPHV Structural Consultants for their generous technical and financial support, as well as the Natural Sciences and Engineering Research

Council of Canada. The finite element computations were conducted on the McGill University supercomputer Guillimin, which is managed by Calcul Québec and Compute Canada. The supercomputer operation is funded by the Canada Foundation for Innovation (CFI), NanoQuébec, RMGA and the Fonds de recherche du Québec - Nature et technologies (FRQ-NT).

\section{References}

[1] AISC 360-16, Specification for structural steel buildings, American Institute of steel Construction, Chicago, IL, 2016.

[2] Steel construction manual, $15^{\text {th }}$ edition, American Institute of steel Construction, Chicago, IL, 2017.

[3] Design examples companion to the aisc steel construction manual, version 15.0, American Institute of steel Construction, Chicago, IL, 2017.

[4] A.R. Tamboli, Handbook of structural steel connection design and details, Third edition, McGraw-Hill, New York, NY., 2016. 
[5] Steel construction manual, $14^{\text {th }}$ edition, American Institute of steel Construction, Chicago, IL, 2011.

[6] CSA-S16-14, Design of steel structures, Canadian Standards Association, Mississauga, ON., 2014.

[7] D.R. Sherman, A. Ghorbanpoor, Design of extended shear tabs, University of WisconsinMilwaukee, Milwaukee, WI, 2002.

[8] J. Hertz, Testing of extended shear tab connections subjected to shear, Master's Thesis, McGill University, Montreal, QC, 2014.

[9] N. Goldstein Apt, Testing of extended shear tab and coped beam-to-girder connections subject to shear loading, Master's Thesis, McGill University, Montreal, QC, 2015.

[10] M. Motallebi, D.G. Lignos, C.A. Rogers, Behavior of stiffened extended shear tab connections under gravity induced shear force., J. Constr. Steel Res., 148 (2018) 336-350.

[11] W. Goodrich, Behavior of extended shear tabs in stiffened beam-to-column web connections, Master's Thesis, Vanderbilt University, Nashville, TN, 2005.

[12] K. Thomas, Design and behaviour of extended shear tabs under combined loads, Master's Thesis, University of Alberta, Edmonton, AB, 2014.

[13] K. Thomas, R.G. Driver, S.A. Oosterhof, L. Callele, Full-scale tests of stabilized and unstabilized extended single-plate connections, Structures, 10 (2017) 49-58.

[14] M. Marosi, M. D’Aronco, R. Tremblay, C.A. Rogers, Multi-row bolted beam to column shear tab connections, 6th European Conference on Steel and Composite Structures, Budapest,Hungary, 2011.

[15] M. Marosi, Behaviour of single and double row bolted shear tab connections and weld retrofits, Master's Thesis, McGill University, Montreal, QC, 2011. 
[16] M. D'Aronco, Behaviour of double and triple vertical rows of bolts shear tab connections and weld retrofits, Master's Thesis, École Polytechnique de Montréal, Montreal, QC, 2013.

[17] A. Mirzaei, Steel shear tab connections subjected to combined shear and axial forces, $\mathrm{PhD}$ Thesis, McGill University, Montreal, QC, 2014.

[18] J. Hertz, D.G. Lignos, C.A. Rogers, Full scale testing of extended beam-to-column and beam to-girder shear tab connections subjected to shear, 8th International Conference on Behavior of Steel Structures in Seismic Areas, Shanghai, China, 2015.

[19] C.A. Rogers, M. Marosi, J. Hertz, D.G. Lignos, R. Tremblay, M. D’Aronco, Performance of weld-retrofit beam-to-column shear tab connections, 8th Int. Workshop on Connections in Steel Structures, Boston, MA., 2016.

[20] ASTM A992 / A992M-11(2015), Standard specification for structural steel shapes, ASTM International, West Conshohocken, PA, 2015.

[21] ASTM A572 / A572M-15, Standard specification for high-strength low-alloy columbiumvanadium structural steel, ASTM International, West Conshohocken, PA, 2015.

[22] AWS D1.1/D1.1M:2015, Structural welding code-steel, American Welding Society, Miami, FL., 2015.

[23] ASTM F3125 / F3125M-15a, Standard specification for high strength structural bolts, steel and alloy steel, heat treated, $120 \mathrm{ksi}(830 \mathrm{mpa})$ and $150 \mathrm{ksi}(1040 \mathrm{mpa})$ minimum tensile strength, inch and metric dimensions, ASTM International, West Conshohocken, PA, 2015.

[24] AISC 341-16, Seismic provisions for structural steel buildings, American Institute of steel Construction, Chicago, IL, 2016.

[25] ASTM A370-17, Standard test methods and definitions for mechanical testing of steel products, ASTM International, West Conshohocken, PA, 2017. 
[26] AWS A5.20/A5.20M:2005 (R2015), Carbon steel electrodes for flux cored arc welding, American Welding Society, Miami, FL., 2015.

[27] A.M. Kanvinde, I.R. Gomez, M. Roberts, B.V. Fell, G.Y. Grondin, Strength and ductility of fillet welds with transverse root notch, J. Constr. Steel Res., 65 (2009) 11.

[28] B. Dowswell, R. Whyte, Local stability of double-coped beams, Eng. J. AISC, 51(1) (2014) 43-52.

[29] J.-J. Cheng, J. Yura, C. Johnson, Design and behavior of coped beams, University of Texas at Austin, Austin, TX, 1984.

[30] L.S. Muir, C.M. Hewitt, Design of unstiffened extended single-plate shear connections, Eng. J. AISC, 46(2) (2009) 67-80.

[31] L. Muir, W. Thornton, A direct method for obtaining the plate buckling coefficient for doublecoped beams, Eng. J. AISC, 41 (2004) 133-134.

[32] A. Astaneh, Demand and supply of ductility in steel shear connections, J. Constr. Steel Res., 14(1) (1989) 1-19.

[33] A. Astaneh, K.M. McMullin, S.M. Call, Behavior and design of steel single plate shear connections, J. Struct. Eng. ASCE, 119(8) (1993) 2421-2440.

[34] ABAQUS 6.11-3, [Computer software], Dassault Systemes Simulia Corp., Providence, RI.

[35] G.L. Kulak, J.W. Fisher, J.H. Struik, Guide to design criteria for bolted and riveted joints, AISC, Chicago,IL, 2001.

[36] ASTM A6 /A6M, General requirements for rolled structural steel bars, plates, shapes, and sheet piling, ASTM International, 2004.

[37] CSA-G40.20-13/G40.21-13, General requirements for rolled or welded structural quality steel/ structural quality steel, Canadian Standards Association, Toronto, ON., 2013. 
[38] CISC, Handbook of steel construction, Canadian Institute of Steel Construction, Markham, ON., 2016.

[39] A. Elkady, D.G. Lignos, Analytical investigation of the cyclic behavior and plastic hinge formation in deep wide-flange steel beam-columns, Bull. Earthq. Eng., 13(4) (2015) 1097-1118. [40] B.A. Mohr, T.M. Murray, Bending strength of steel bracket and splice plates, Eng. J. AISC, 45(2) (2008) 97-106.

[41] P. Salem, Unified design criteria for steel cantilever plate connection elements, PhD Thesis, University of Alberta, Edmonton, AB, 2016.

[42] M. Motallebi, Behavior of extended shear tab connections under combined axial and shear forces, PhD Thesis, McGill University, Montreal, QC, 2018.

[43] B.G. Neal, The effect of shear and normal forces on the fully plastic moment of a beam of rectangular cross section, Journal of Applied Mechanics, 28(2) (1961) 269-274.

[44] A. Astaneh, Seismic behavior and design of gusset plates, Steel Tips, Structural Steel Education Council, Moraga, CA., 1998. 